NBER WORKING PAPER SERIES

\title{
MONETARY POLICY ISSUES FOR THE EUROSYSTEM
}

\author{
Lars E.O. Svensson
}

Working Paper 7177

http://www.nber.org/papers/w7177

\author{
NATIONAL BUREAU OF ECONOMIC RESEARCH \\ 1050 Massachusetts Avenue \\ Cambridge, MA 02138 \\ June 1999
}

This paper was presented at the Carnegie-Rochester Conference on Issues Regarding European Monetary Integration, Pittsburgh, November 20-21, 1998. I am grateful for comments from the discussant Dale Henderson, the editor Bennett McCallum, Ignazio Angeloni, Claes Berg, Stefan Gerlach, Otmar Issing, Henrik Jensen, Allan Meltzer, Francisco Nadal de Simone, Maurice Obstfeld, Stefan Palmqvist, Dagfinn Rime and Scott Roger as well as participants in seminars at IIES and IMF and in the FRBSF-SIEPR Conference on Monetary Policy and Monetary Institutions, Stanford University, March 1999. I also thank Thomas Eisensee and Marcus Salomonsson for research assistance, and Christina Lönnblad for editorial and secretarial assistance. The views expressed and any errors are my own responsibility. All opinions expressed are those of the authors and not those of the National Bureau of Economic Research.

(C) 1999 by Lars E.O. Svensson. All rights reserved. Short sections of text, not to exceed two paragraphs, may be quoted without explicit permission provided that full credit, including $(\mathbb{C}$ notice, is given to the source. 
Monetary Policy Issues for the Eurosystem

Lars E.O. Svensson

NBER Working Paper No. 7177

June 1999

JEL No. E42, E52, E58

\section{ABSTRACT}

The paper discusses the choice between inflation targeting and monetary targeting as a strategy for the Eurosystem, the actual strategy the Eurosystem announced in the fall of 1998, the framework for policy decisions appropriate for achieving the goals of the Eurosystem, the role of exchange rate management in the EMU, and the accountability and transparency of the Eurosystem. The choice between inflation targeting and monetary targeting is, in effect, a choice between high and low transparency. Inflation targeting and monetary targeting, in practice, imply similar policy decisions, but monetary targeting implies that policy decisions are explained in terms of money-growth developments that are not essential for policy. The Eurosystem has specified an operational inflation target, although in a somewhat ambiguous way. More importantly, its announced monetary strategy is deficient, since it proposes a prominent role for an essentially irrelevant money-growth indicator in analysis and communication, but will keep secret the inflation forecast that will, in practice, be the decisive input in policy decisions. Exchange rate policy is controlled by the Council of finance ministers in the EMU; this is a major inconsistency in the Maastricht Treaty and a possible threat to the independence of the Eurosystem. The European Parliament may have a crucial role in ensuring the accountability of the Eurosystem; the minimum transparency needed for effective outside monitoring and evaluation of the Eurosystem's policy decisions seem to require published inflation forecasts and, most likely, published minutes and voting records of the Governing Council.

\section{Lars E.O. Svensson}

Institute for International Economic Studies

Stockholm University

10691 Stockholm

Sweden

and NBER

Lars.Svensson@iies.su.se 


\section{Introduction}

The purpose of this paper is to discuss some monetary policy issues for the Eurosystem, which conducts monetary policy in the Euro area from January 1, 1999. ${ }^{1}$ More precisely, the paper discusses the choice between inflation targeting and monetary targeting as a strategy for the Eurosystem, the actual strategy the Eurosystem announced in the fall of 1998, the framework for policy decisions appropriate for achieving the goals of the Eurosystem, the role of exchange rate management in the EMU, and the accountability and transparency of the Eurosystem.

Some of the findings of the papers are that the choice between inflation targeting and Bundesbank-style "pragmatic" monetary targeting is, in effect, a choice between high and low transparency. Inflation targeting and pragmatic monetary targeting, in practice, imply similar policy decisions, but pragmatic monetary targeting implies that policy decisions are explained in terms of money-growth developments that are not essential for policy. As a part of its monetary strategy, the Eurosystem has specified an operational inflation target, although in a somewhat ambiguous way. More importantly, its announced monetary strategy is deficient, since it proposes a prominent role for an essentially irrelevant money-growth indicator in analysis and communication, but will keep secret the inflation forecast that will, in practice, be the decisive input in policy decisions. Exchange rate policy is controlled by the Council of finance ministers in the EMU; this is a major inconsistency in the Maastricht Treaty and a potential threat to the independence of the Eurosystem. The European Parliament may play a crucial role in ensuring the accountability of the Eurosystem; the minimum transparency needed for effective outside monitoring and evaluation of the Eurosystem's policy decisions requires published inflation forecasts and, most likely, published minutes and voting records of the Governing Council.

Section 2 discusses the Eurosystem's choice of monetary strategy, section 3 discusses the Eurosystem's announcement of October 13, 1998, section 4 discusses the appropriate targets and operating procedures for the Eurosystem, section 5 discusses exchange rate policy, and section 6 discusses the appropriate degree of transparency. Section 7 contains some conclusions.

${ }^{1}$ The "Eurosystem," a "user-friendly expression" adopted by its General Council, consists of the European Central Bank, ECB, and the national central banks, NCBs, of the 11 Member States adopting the euro. Decisions in the Eurosystem are made by the 17 members of the Governing Council, consisting of the 6 members of the Executive Board of the ECB and the 11 governors of the NCBs. The European System of Central Banks, ESCB, also includes the 4 NCBs in the European Union that have not adopted the Euro.

The relation between ECB and the Eurosystem is somewhat similar to that between the Federal Reserve Board and the Federal Reserve System (the latter includes the Federal Reserve Banks). Since monetary policy will be decided by the ESCB's Governing Council rather than by the ECB's Executive Board, it is logical to speak of the monetary policy of the Eurosystem rather than that of the ECB. 
In spite of the length of this paper, several important issues are not covered, for instance, potential problems with the relatively weak center and the high degree of decentralization in the Eurosystem, issues of financial stability and lending of last resort, fiscal interaction, and international monetary coordination. ${ }^{2}$

\section{The choice of monetary strategy for the Eurosystem: inflation targeting or monetary targeting?}

The choice of monetary strategy for the Eurosystem was previously narrowed down by EMI [32] to be between inflation targeting (practiced by the central banks in New Zealand, Canada, United Kingdom, Sweden and Australia) and monetary targeting (practiced by the Bundesbank in Germany), or possibly a combination of these two alternatives. ${ }^{3}$ Exchange-rate targeting, interest-rate targeting and nominal-GDP targeting was considered inappropriate (EMI [32], p. 1):

"First, an exchange rate objective is not considered appropriate since, for an area potentially as large as the euro area, such an approach might be inconsistent with the internal goal of price stability. Second, the use of an interest rate as an intermediate target is not considered appropriate given difficulties in identifying the equilibrium real interest rate which would be consistent with price stability. Third, employing the growth rate of nominal GDP which can be viewed as consistent with price stability as an intermediate target would provide a clear nominal framework and would have the advantage of not being sensitive to shocks in the income velocity of money. However, nominal income would be difficult to control by the ESCB, could lead to misinterpretation of the ultimate goal of the ESCB, could be subject to substantial data revisions and might lead to an indeterminate price/volume division in the short run, thus creating uncertainty about the inflation performance of the economy. Furthermore, the fact that nominal income targeting is not used at present in any EU Member State makes it inadvisable for the ESCB to adopt this strategy. For these reasons, special attention is paid in this report to only two strategies, monetary and direct inflation targeting."

There has been considerable debate about the Eurosystem's monetary strategy among academics and central bankers. Inflation targeting has been promoted by a large majority of academics as well as by central bankers with experience of inflation targeting and previous failures

\footnotetext{
${ }^{2}$ These issues are discussed in, for instance, Begg [3], Begg, Giavazzi and Wyplosz [5], Begg, De Grauwe, Giavazzi, Uhlig and Wyplosz [4], Obstfeld [56] and the report by Blanchard, Gros, Emerson, Mayer, Saint-Paul, Sinn and Tabellini [42].

${ }^{3}$ Finland and Spain have announced inflation targets while still being members of the ERM, the Exchange Rate Mechanism of the European Union. Israel has announced inflation targets while still maintaining an exchange rate band. Recently the Czech Republic joined the ranks of inflation-targeting countries.

The National Bank of Switzerland also has a monetary target. The discussion about monetary targeting in the EMU has almost exclusively focused on Bundesbank-style monetary targeting, though.
} 
of monetary targeting in non-German countries. Monetary targeting has mainly been promoted by certain German academics and by German central bankers. More recently, central bankers in Germany and in the Eurosystem have suggested a combination of the two alternatives. On October 13, 1998, the Eurosystem finally announced its strategy, indeed with elements of both alternatives. The Eurosystem's decision is discussed and scrutinized in section 3. In that section I will provide definitions and some general discussion of the two alternatives, that is, inflation targeting and monetary targeting.

In discussing monetary policy strategy, I will distinguish two of its elements, the framework for policy decisions and communication. By the framework for policy decisions, I mean the monetary policy procedures inside the central bank, which, from observations of various indicators, eventually result in decisions about the central bank's instruments, that is, decisions intended to achieve the central bank's targets; in short, the principles for setting the instruments (which, in the case of the Eurosystem, will be a repurchase rate). ${ }^{4}$ By communication, I mean the central bank's way of communicating with outsiders (the general public, the financial market, governments, policymakers and policymaking institutions, which, in the case of the Eurosystem, includes EU institutions and national governments and parliaments). Communication is part of the implementation of monetary policy, in that it affects the efficiency of monetary policy by, for instance, influencing expectations, predictability and credibility of the policy. Communication also influences how transparent policy is, which is crucial for the accountability and, arguably, also for the political legitimacy of the policy.

\subsection{Inflation targeting}

Inflation targeting, as practised by an increasing number of inflation-targeting central banks, has three main characteristics, (1) an explicit quantitative inflation target, (2) a framework for policy decisions, inflation-forecast targeting, which uses an internal conditional inflation forecast as an intermediate target variable, and (3) a high degree of transparency and accountability. Real-world inflation targeting is "flexible" inflation targeting rather than "strict", in the sense that it allows concerns not only about inflation variability around the inflation target but also about real variability in the economy. ${ }^{5}$ This can be represented by an intertemporal loss function

\footnotetext{
${ }^{4}$ Possible alternative terms are "decision process," "implementation" (in the broad sense of implementation of the monetary-policy goals rather than in the narrow sense of the implementation of a particular monetary policy decision) or "operating procedures" (as it is used in Freedman's [37] paper for the 1996 Jackson Hole conference) The last term has nevertheless been avoided here, since it is frequently used in the United States in reference to the choice and the use of an operating target, like non-borrowed reserves or the federal-funds rate.

5 See, for instance, Svensson [70] for discussion and references to the literature.
} 
in period $t$,

$$
\mathrm{E}_{t}(1-\delta) \sum_{\tau=0}^{\infty} \delta^{\tau} L_{t+\tau},
$$

where $\mathrm{E}_{t}$ denotes expectations conditional on information available in period $t$, the discount factor, $\delta$, fulfills $0<\delta<1$ and the period loss function is given by

$$
L_{t}=\frac{1}{2}\left[\left(\pi_{t}-\pi^{*}\right)^{2}+\lambda\left(y_{t}-y_{t}^{n}\right)^{2}\right]
$$

where $\pi_{t}$ is inflation in period $t, \pi^{*}$ is the inflation target, $y_{t}$ is $(\log )$ output, $y_{t}^{n}$ is $(\log )$ potential output, and $y_{t}-y_{t}^{n}$ is the output gap, with $\lambda>0$ being the relative weight on output-gap stabilization. As emphasized in the literature, this translates into a more gradual adjustment of inflation towards the inflation target, and an aim at the inflation target at a longer horizon than the shortest possible. ${ }^{6}$ Furthermore, a loss function as above implies that the conditional inflation forecast will become an intermediate target at an appropriate horizon, say about two years ahead. The framework for policy decisions of the central bank is then to compute conditional forecasts for inflation and, possibly, for the output gap and then set its instrument, normally a short interest rate, such that the corresponding conditional inflation forecast about two years ahead hits the inflation target. ${ }^{7}$

It is worth pointing out that under this framework for policy decisions, the instrument will depend on all the information entering the conditional forecasts, including the current inflation and output gap. In particular, note that the current output gap will also affect the instrument under hypothetical strict inflation targeting, when $\lambda=0$ and the output gap does not enter the loss function - for the simple reason that the current output gap helps predict future inflation.

Communication under inflation targeting is mostly direct and to the point. The Reserve Bank of New Zealand, Bank of England and Sveriges Riksbank publish high-quality Inflation Reports with conditional inflation forecasts, where they motivate their policy and explain ex

\footnotetext{
6 See Ball [2] and Svensson [68].

7 The loss function above does not induce an average inflation bias, since the implicit output target is taken to be the potential output level and therefore consistent with the potential-rate hypothesis (that monetary policy cannot systematically affect average unemployment/the potential output level). Indeed, motivations for inflation targeting, by governments, parliaments and central banks, put much emphasis on the potential-rate hypothesis, and it can be argued that the hypothesis constitutes one of the foundations of inflation targeting. The high degree of transparency and accountability in inflation targeting may then ensure that any concern about the real economy is consistent with the natural-rate hypotheses and therefore reduces, or eliminates, any inflation bias. This then translates into an output-gap target in (2) that is equal to zero.

This highlights a fundamental asymmetry between inflation and output in inflation targeting. There is both a level goal and a stability goal for inflation, and the level goal (that is, the inflation target) is subject to choice. For output, there is only a stability goal and no level goal. Or, to put it differently, the level goal is not subject to choice; it is given by the capacity output level. Therefore, I believe it appropriate to label minimizing (2) as "(flexible) inflation targeting" rather than "inflation-and-output-gap targeting," especially since the label is already used for the monetary policy regimes in New Zealand, Canada, United Kingdom, Sweden and Australia.
} 
post outcomes. Bank of England and Sveriges Riksbank also publish voting records and nonattributed minutes from the meeting of their respective Monetary Policy Committee and Executive Board. This makes inflation targeting very transparent, simplifies external monitoring and evaluation of the policy, improves incentives for the central banks to perform well, and increases the accountability of the central banks.

Thus, under inflation targeting, the central bank's rhetoric is highly consistent with the actual policy pursued. Given the high degree of transparency, significant discrepancies are not difficult to detect by competent central-bank watchers. ${ }^{8}$

\subsection{Monetary targeting}

Whereas the rhetoric and the practice coincide under inflation targeting, this is arguably not always the case under monetary targeting. Therefore, monetary targeting must be defined with some special care. I will specify two kinds of monetary targeting, "strict" money-growth targeting (which is hypothetical and not pursued by any central bank) and "pragmatic" monetary targeting (which is the policy that was actually pursued by Bundesbank).

\subsubsection{Strict money-growth targeting}

First, let me define strict money-growth targeting. ${ }^{9}$ This involves specifying a money-growth target for a monetary aggregate, say M3. The money-growth target is set so as to be consistent with an inflation target (in the sense of achieving an average inflation equal to the inflation target). Strict money-growth targeting can be represented by the period loss function

$$
L_{t}=\frac{1}{2}\left(\Delta m_{t}-\Delta m^{*}\right)^{2}
$$

where $m_{t}$ denotes the (log) quantity of money in period $t, \Delta m_{t} \equiv m_{t}-m_{t-1}$ denotes money growth, and $\Delta m^{*}$ is the money-growth target. Since money growth reacts with some lag to the interest rate, the framework for policy decisions involves making a conditional forecast for money growth and setting the interest rate such that the conditional forecast hits the target at the appropriate horizon.

\footnotetext{
${ }^{8}$ During the first few years, inflation-targeting central banks were arguably less than transparent about the role of output-gap stabilization. This has, by now, to a large extent been remedied; see, for instance, the discussion in Svensson [70].

9 By "strict" targeting of a variable I mean that no other variable enters the loss function; "flexible" targeting allows other variables in the loss function. By "unconditional" targeting, I mean that the target level is fixed for a substantial period; "conditional" money-growth targeting, discussed in Svensson [68] and [70] and, briefly, in appendix B of the conference version of this paper, allows the target level to be state-contingent and adjusted with new information.
} 
In any reasonable model of the transmission mechanism, minimizing the loss function (3) is not equal to minimizing the loss function (2). This simply reflects that money is not an intermediate variable in the transmission mechanism from the instrument to inflation. It is not the case that the instrument affects inflation in the medium term exclusively by first affecting money growth (with a lag), and then by money growth affecting inflation. ${ }^{10}$ As a consequence, although a money-growth target may result in the desired average inflation rate over a sufficiently long period, in the medium term there is a conflict between stabilizing money-growth and stabilizing inflation. Thus, there is a tradeoff between inflation variability and money-growth variability. This is particularly clear if we consider strict inflation targeting, that is, with $\lambda=0$ in (2). Strict inflation targeting minimizes inflation variability around the inflation target, which would normally lead to substantial money-growth variability. Money-growth targeting minimizes money-growth variability around the money-growth target, which can be chosen such that average inflation equals the inflation target, but money-growth targeting would normally lead to considerable inflation variability around the inflation target. This is illustrated in figure 1 , where the curve illustrates the efficient tradeoff between inflation variability and money-growth variability. Strict inflation targeting minimizes inflation variability at the point SIT, whereas money-growth targeting minimizes money-growth variability at the point SMT. ${ }^{11}$

In terms of the frequently used tradeoff between inflation variability and output-gap variability, shown in figure 2, flexible inflation targeting would correspond to a compromise between inflation and output-gap variability at the point FIT, whereas strict monetary targeting would correspond to a point inside the efficient tradeoff, like the point SMT. ${ }^{12}$ Rudebusch and Svensson [63] confirm the empirical relevance of figure $2 .{ }^{13}$

10 By an intermediate variable in the transmission mechanism I mean a variable such that the instrument affects a target variable exclusively via first affecting the intermediate variable and then the intermediate variable affecting the target variable. Money is simply not an intermediate variable in this sense. See the simple model of the transmission mechanism below, and see Svensson [70] for further discussion. Early discussion of these issues can be found in Friedman [38] and Bryant [14].

${ }_{11}$ The curve results for a period loss function (2) replaced by $L_{t}=\frac{1}{2}\left[(1-\omega)\left(\pi_{t}-\pi^{*}\right)^{2}+\omega\left(\Delta m_{t}-\Delta m^{*}\right)^{2}\right]$ and an intertemporal loss function like $(1)$ below (where $\delta \rightarrow 1$ ), and where $\omega$ varies from zero (resulting in point SIT) to unity (resulting in point SMT).

12 The curve results for a period loss function $(2)$ and an intertemporal loss function like (1) (where $\delta \rightarrow 1$ ), and where $\lambda$ varies from zero (resulting in point SIT) to infinity [resulting in the minimum output-gap variability but potentially a nonstationary inflation, indicated by point SOT (for "strict output targeting") potentially being infinitely far to the right].

${ }^{13}$ The general inefficiency of any intermediate-targeting strategy, including monetary targeting, was pointed out by Kareken, Muench and Wallace [49], Friedman [38] and Bryant [14] in early criticism of monetary targeting. 
Figure 1: The tradeoff between inflation and money-growth variability, $\operatorname{Var}\left[\pi_{t}\right]$ and $\operatorname{Var}\left[\Delta m_{t}\right]$.

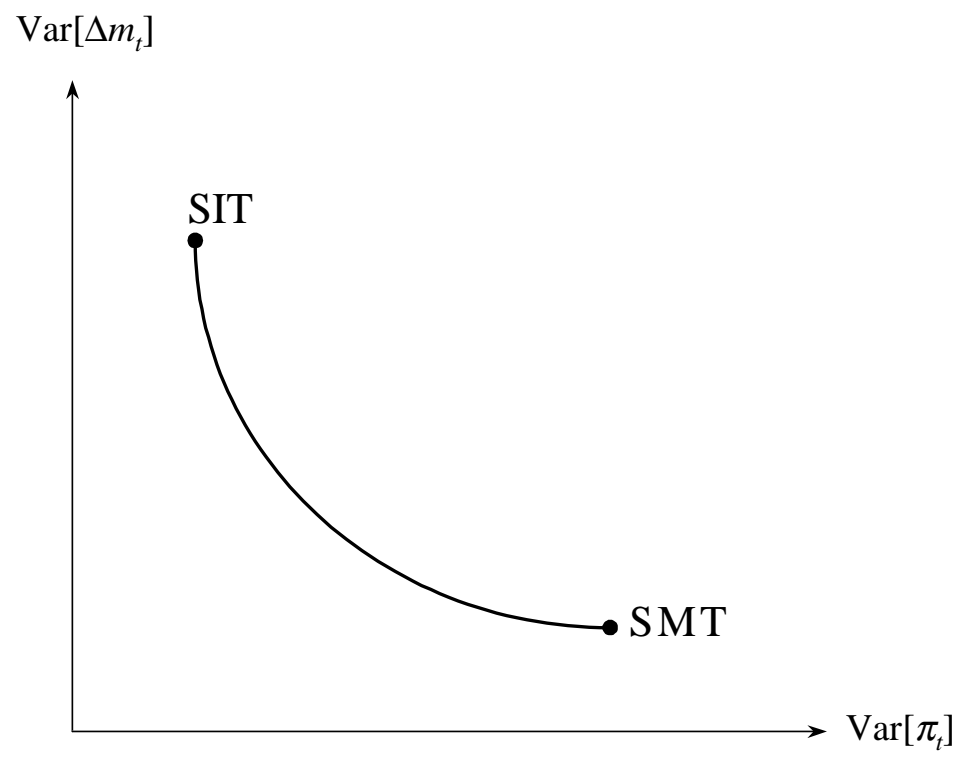

\subsubsection{Pragmatic monetary targeting}

Strict money-growth targeting means giving priority to the money-growth target when conflicts with the inflation target arise. This would lead to high inflation variability, as illustrated in figure 2 and empirically confirmed in Rudebusch and Svensson [63]. This is probably the very reason why Bundesbank is notorious for disregarding its money-growth targets, and hence not implementing strict money-growth targeting. Instead, Bundesbank engages in what has been called pragmatic monetary targeting.

Pragmatic monetary targeting involves having an inflation target, over the years called "unavoidable inflation", "price norm", or "medium-term price assumption". It has been 2 percent for many years. Since the Bundesbank's Council's meeting in December 1996 through 1998, it has been 1.5-2 percent. ${ }^{14}$ Starting from this inflation target, Bundesbank has then, for each year, derived a money-growth target for M3 by adding predicted potential-output growth and subtracting a velocity trend. Bundesbank has then set a target corridor around the monetary target, for 1998 it was 3 percentage points wide.

As noted above, the problem is now that in the medium term, there will normally be a

\footnotetext{
${ }^{14}$ In Bundesbank [18, p. 21], this interval is referred to as "[Bundesbank's] medium-term price assumption, which is a definitive expression of its price stability target."
} 
Figure 2: The tradeoff between inflation and output-gap variability, $\operatorname{Var}\left[\pi_{t}\right]$ and $\operatorname{Var}\left[x_{t}\right]$.

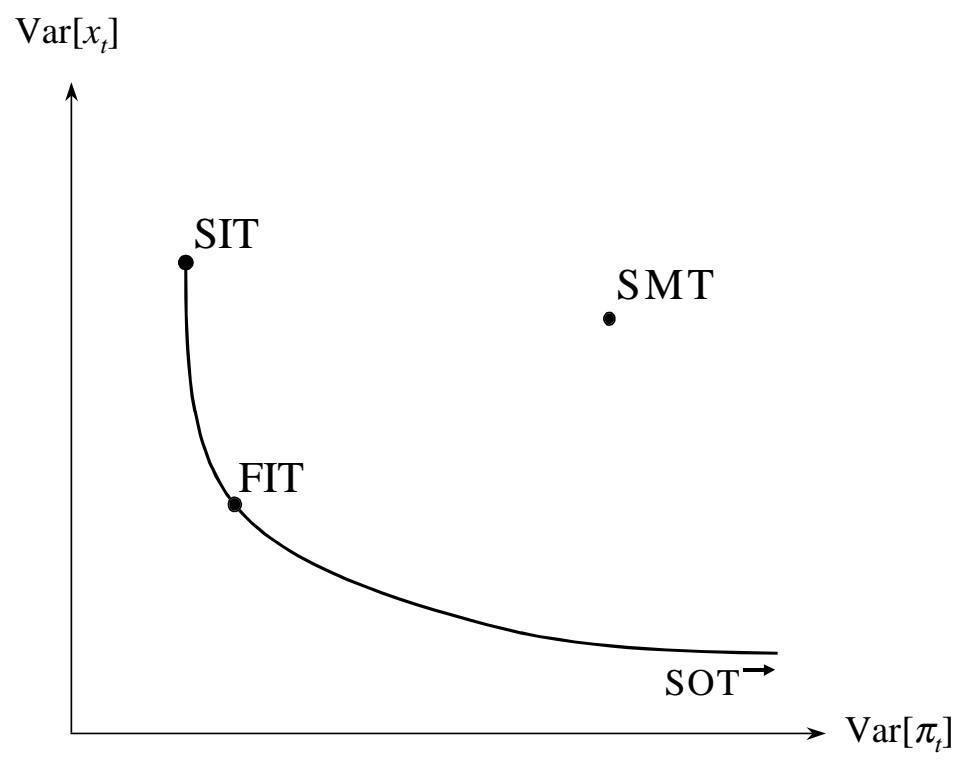

conflict between stabilizing inflation around the inflation target and stabilizing money-growth around the monetary target. A number of studies of Bundesbank's monetary policy, by both German and non-German academics, have come to the unanimous conclusion that, in this conflict, Bundesbank has given priority to the inflation target and has disregarded the monetary target. ${ }^{15}$ One piece of evidence is from estimates and interpretations of Bundesbank's reaction function. These show no trace of reacting to current or anticipated misses of the money-growth targets. ${ }^{16}$ The evidence for this conclusions includes the fact that Bundesbank's inflation record has been unprecedented, while it has missed its money-growth target about half the time. A graph from Bundesbank's Annual Report 1995, [17], is most revealing, see figure 3. Furthermore, these misses seem deliberate and are hardly due to imperfect control. Figure 4 shows the German overnight interest rate (which is highly correlated with the Bundesbank's repurchase rate) and the German CPI inflation during 1993-1996. There is no sign of dramatic interest-rate changes in order to bring money in line with the monetary target, whereas inflation seems to be under control. Indeed, according to Issing's [44, p. 71-72] evaluation of German monetary policy:

\footnotetext{
${ }^{15}$ This literature includes Neumann [55], von Hagen [79], Bernanke and Mihov [7], Clarida and Gertler [21], Clarida, Gali and Gertler [20] (note a crucial typo: the coefficient for money supply in Table 1 should be 0.07 instead of 0.7), Laubach and Posen [50], and Bernanke, Laubach, Mishkin and Posen [6].

${ }^{16}$ Depending on the form of the money-demand function, there are, however, some difficulties in interpreting reaction functions consistent with monetary targeting, cf. Svensson [70].
} 
"Only rarely have money stock overshoots been of a completely involuntary nature; mostly rather they constituted deliberate monetary policy decisions.... $[\mathrm{M}]$ onetary policy was always analyzed with a view to achieve the ultimate aim of safeguarding the currency."

Figure 3: Growth of German M3 (Chart 12 in Deutsche Bundesbank [17])

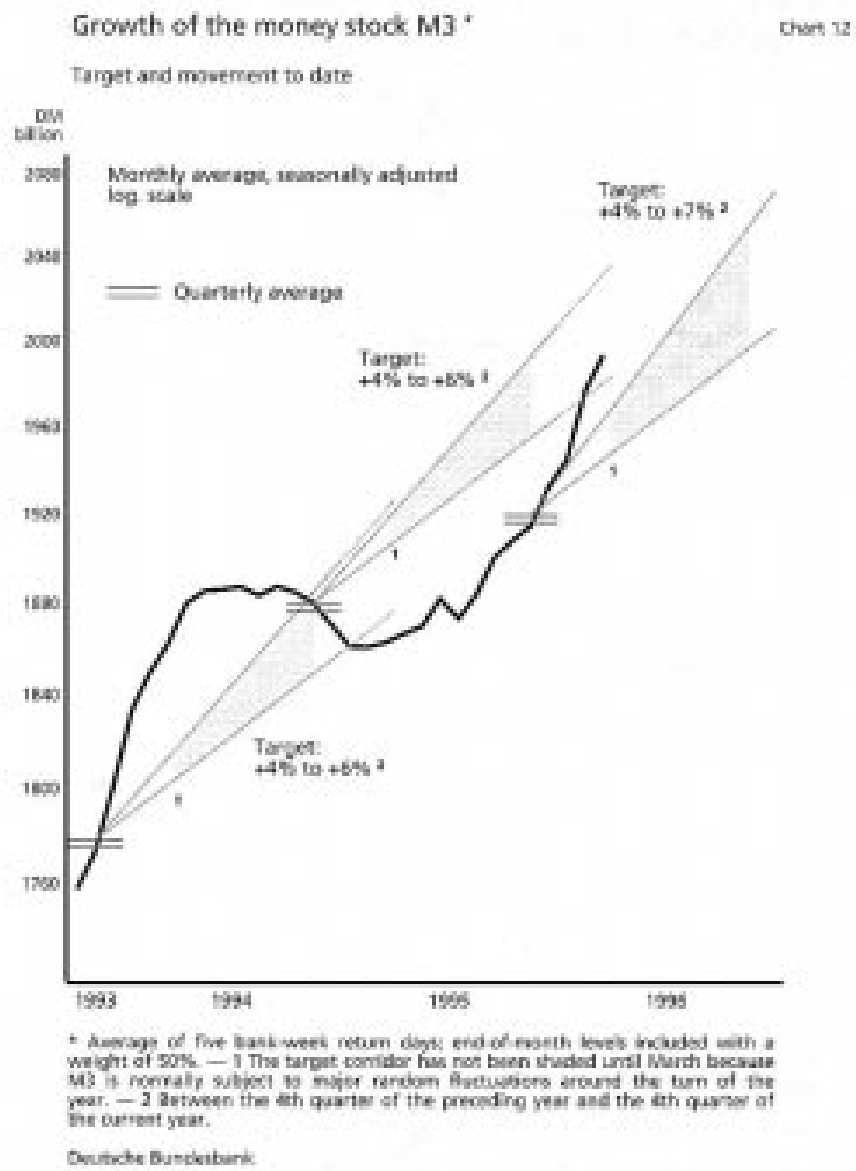

Although Bundesbank's internal framework for policy decisions is a well-kept secret, it seems inconceivable that it could have achieved its inflation record without a forward-looking mediumterm approach to monetary policy, where conditional inflation forecasts are an important element. My conclusion is that pragmatic monetary targeting is likely to have a framework for policy decisions similar to flexible inflation targeting. I interpret von Hagen [79] and [80] as previously having come to the same conclusions. Thus, Bundesbank's policy can be seen as having the same period loss function as flexible inflation targeting, (2), rather than that corresponding to strict money-growth targeting, (3), and would reach a point like FIT in figure 2.

The major difference between inflation targeting and pragmatic monetary targeting is then 


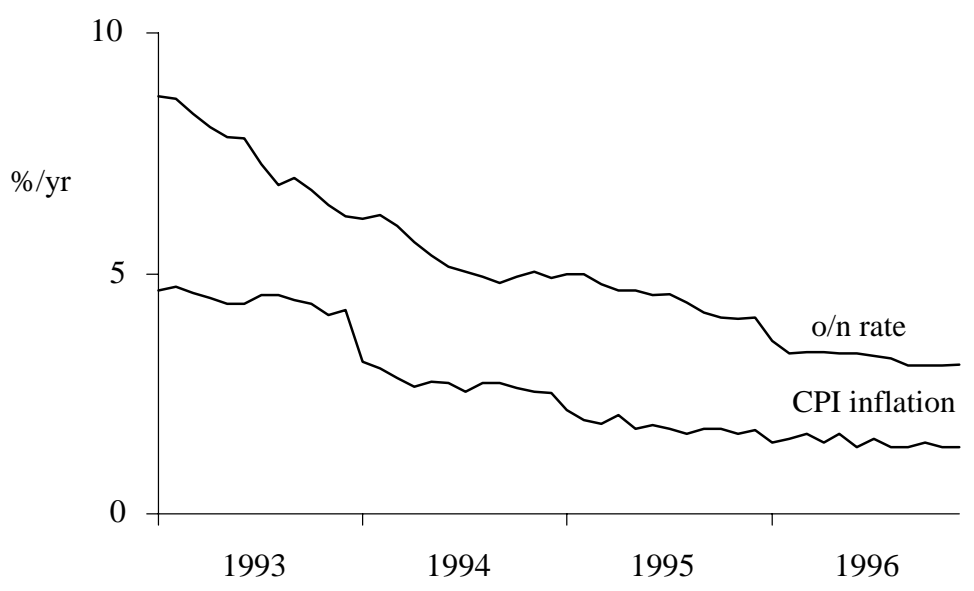

Bundesbank's communication with outsiders. Bundesbank communication was entirely within the monetary targeting framework, with frequent ad hoc explanations of the regular misses of the monetary target. Given that the framework for policy decisions in reality seems to disregard the monetary targets, the discussion about the misses of the monetary targets was basically irrelevant for Bundesbank's monetary policy. Thus, pragmatic monetary targeting can be described as "inflation targeting in disguise", or "inflation targeting in actions, monetary targeting in words." The rhetoric was simply inconsistent with the framework for policy decisions. ${ }^{17} 18$

What explains this strange state of affairs? von Hagen [80] provides a fascinating account of the rise of Bundesbank's monetary-targeting framework. His account provides ample evidence that the framework was important and perhaps crucial in the sometimes delicate political situation of Bundesbank, where its role was mainly to increase and maintain Bundesbank's independence and protect it from political interference. ${ }^{19}$

17 In line with the discussion in Lohmann [52], there may have been two very different audiences for the Bundesbank's announcements. One, the experts, was informed and saw through the rhetoric and understood the true reasons for repeated misses of the monetary targets. The other, the general public, was uninformed and believed that the monetary-targeting framework was essential.

${ }^{18}$ Posen [60] has coined the term "monetary masquerade".

19 One easily recalls an argument sometimes presented in favor of the nontranspareny of the Federal Reserve System; nontransparency is a way of keeping Congress at arms-length and maintain independence. 


\subsection{Summary}

Inflation targeting and pragmatic monetary targeting appear to be similar with regard to the loss function and the framework for policy decisions. The difference regards communication and transparency. Under inflation targeting, communication is direct and to the point. The rhetoric is consistent with the framework for policy decisions. Words match actions, and vice versa. Inflation targeting is "inflation targeting in the open," whereas pragmatic monetary targeting is "inflation targeting in disguise." Under pragmatic monetary targeting, the communication and discussion is, deliberately, mainly focused on irrelevant misses of the monetary targets and the ad hoc explanations thereof. In practice, the choice between inflation targeting and pragmatic monetary targeting is a choice between transparency and nontransparency. ${ }^{20} 21$ Given this, I believe the advocacy of monetary targeting for the Eurosystem has been somewhat misguided. ${ }^{22}$

\section{The Eurosystem's monetary policy strategy}

The goals for monetary policy in the EMU are specified in the Maastricht Treaty. According to its Article 105(1),

"The primary objective of the ESCB shall be to maintain price stability. Without prejudice to the objective of price stability, the ESCB shall support the general economic policies in the Community with a view to contributing to the achievement of the objectives of the Community as laid down in Article 2..."

According to Article 2, the Community shall have as its task

"to promote throughout the Community a harmonious and balanced development of economic activities, sustainable and non-inflationary growth respecting the environment, a high degree of convergence of economic performance, a high level of employment and of social protection, the raising of the standard of living and quality of life, and economic and social cohesion and solidarity among Member States."

EMI [32] and the Executive Board of the ECB [33] have previously defined price stability as an inflation rate between 0 and 2 percent (per year). This could be interpreted as a target range for an EMU-wide inflation of 0-2 percent, or as a point inflation target of 1 percent with a tolerance interval of \pm 1 percentage point. ${ }^{23}$

\footnotetext{
${ }^{20}$ Thus, I agree with Laubach and Posen [50] in their detailed description of actual Bundesbank policy, but I disagree with their conclusion that Bundesbank's pragmatic monetary targeting is, nevertheless, transparent.

${ }^{21}$ See Schmid [64] for a recent official Bundesbank view of its monetary targeting.

${ }^{22}$ In appendix D of the conference version of this paper, I scrutinize the arguments in favor of monetary targeting that have been put forward by EMU Monitor, a panel of European academics.

${ }_{23}$ Alternatively, it might be interpreted as implying that a point inflation target is not necessarily at the midpoint but somewhere within the interval 0-2 percent.
} 
The second sentence in Article 105(1) could arguably be interpreted as including stabilization of real variables around their natural (potential) levels, that is, flexible rather than strict inflation targeting. This could be represented by a Eurosystem period loss function including stabilization of the output gap, as in (2) with $\lambda>0$. As emphasized in the literature and noted above, this translates into a gradual adjustment of inflation towards the inflation target, and aims at the inflation target at a longer horizon. Furthermore, a loss function as above implies that the conditional inflation forecast will become an intermediate target at an appropriate horizon, say 2-2.5 years ahead. The task of the Eurosystem would then be to set its instrument, an EMUwide short nominal interest rate, such that the corresponding conditional inflation forecast 2-2.5 years ahead hits the inflation target of 1 percent per year.

After its meeting on October 13, 1998, the Governing Council of the ECB finally announced the main elements of its monetary policy strategy, namely (see [30]):

"• a quantitative definition of the primary objective of the single monetary policy, price stability;

- a prominent role for money with a reference value for the growth of a monetary aggregate; and

- a broadly-based assessment of the outlook for future price developments."

\subsection{The definition of price stability}

With reference to the primary objective for the Eurosystem to maintain price stability, the Governing Council announced on October 13 that

"the ESCB's monetary policy strategy will focus strictly [emphasis added] on this objective."

This might be interpreted as $\lambda=0$, a zero weight on output-gap stabilization, corresponding to strict inflation targeting rather than flexible.

Furthermore, the Governing Council adopted the following definition of price stability:

"Price stability shall be defined as a year-on-year increase in the Harmonised Index of Consumer Prices (HICP) for the euro area [the Monetary Union Index of Consumer Prices (MUICP)] of below 2\%. Price stability is to be maintained over the medium term. The current rate of HICP inflation in the euro area [1.2\% for August 1998, $1.0 \%$ for September] is in line with this objective."

As commentators quickly pointed out, this definition of price stability was indeed ambiguous, since it did not specify a lower bound for inflation. About a month later, on November 10, it 
appeared that the ambiguity was eliminated, when the ECB president, Willem Duisenberg [26], clarified that "increase" in the definition excludes decrease and deflation. It would seem to follow that the lower bound was zero and that the definition refers to an inflation rate between 0 and 2 percent. This would have been consistent with the previous statements of EMI and the Executive Board referred to above. The midpoint of the interval would then be close to the August MUICP inflation rate and equal to the September rate, and thus certainly "in line with this objective." Thus, the midpoint of 1 percent could have been taken to be the inflation target $\pi^{*}$ and serve as an anchor for inflation expectations. ${ }^{24}$

The ambiguity was not completely resolved, though. On November 12, Duisenberg [27] stated:

"We did not announce a floor for inflation, because we know that the price index may include a measurement bias, but we do not know its magnitude."

To this date (May 1999), no explicit lower bound has been announced.

A lower bound might be inferred from the reference value for money growth, though. When the reference value was announced on December 1, [29], it appeared that a point inflation target of 1.5 percent had been used (see further below). If that point inflation target is interpreted to be in the middle of the interval, the lower bound is 1 percent. Hence, it seems to me that the definition could also be interpreted as the interval 1-2 percent, equivalent to an inflation target of 1.5 percent.

Is an inflation target of 1.5 percent appropriate? It happens to coincide with the midpoint of the target range of 0-3 for New Zealand since 1997 (during the period 1990-1996, the target range was $0-2$ percent). The fact that the inflation target exceeds zero can be motivated by measurement bias, nonnegative nominal interest rates and possible downward nominal price and wage rigidities. The other inflation-targeting countries now have inflation targets (or midpoints of the target range) ranging between 1.5 in New Zealand, 2 percent in Canada, Sweden and Finland (before joining the EMU), and 2.5 percent in United Kingdom and Australia (the Reserve Bank of Australia has an inflation target in the form of the range 2-3 percent for average inflation over an unspecified business cycle). As noted above, Bundesbank had 1.5-2 percent (which could hence be translated into a point inflation target of 1.75 percent); thus, the

\footnotetext{
${ }^{24}$ Could the definition indicate an inflation target $\pi^{*}$ just below 2 percent? (" 2.5 percent or less," the ambiguous inflation target for Bank of England announced by the Chancellor of the Exchequer in June 1995, was later interpreted as just below 2.5 percent; the current unambiguous target of 2.5 percent was announced in May 1997). This can hardly be the case, since such an inflation target, if successful, would mean that inflation would exceed 2 percent about 50 percent of the time, due to unavoidable short-term volatility.
} 
Eurosystem seems to be aiming slightly lower than the Bundesbank. Interestingly, 2 percent is the borderline in Akerlof, Dickens and Perry [1], who study the effects of downward rigidity of nominal wages, whereas 1 percent is the borderline in Orphanides and Wieland [57], who examine the consequences of non-negative nominal interest rates. These studies indicate that inflation targets below those borderlines risk reducing average output or increasing average unemployment. ${ }^{25}$ Altogether, announcing an explicit inflation target (a point target or a range) may be more important than whether the target (the midpoint of the range) is $1.5,2$ or 2.5 percent.

The Governing Council also stated:

"Furthermore, the statement that "price stability is to be maintained over the medium term' reflects the need for monetary policy to have a forward-looking, medium-term orientation. It also acknowledges the existence of short-term volatility in prices which cannot be controlled by monetary policy."

This could be interpreted as targeting inflation at a longer horizon than the minimum possible, which is consistent with flexible inflation targeting and $\lambda>0$. The Eurosystem will probably target inflation at approximately a two-year horizon, as is done by most inflation-targeting central banks do. A quote from the January Monthly Bulletin [31, p. 47] gives additional support for an interpretation with $\lambda>0$, as well as some weight on minimizing interest rate variability:

“... a medium-term orientation of monetary policy is important in order to permit a gradualist and measured response [to some threats to price stability]. Such a central bank response will not introduce unnecessary and possibly self-sustaining uncertainty into short-term interest rates or the real economy..." 26

\subsection{A prominent role for money; a major role for an inflation forecast}

The Governing Council also announced that the monetary policy strategy would consist of "two key elements," later called "the two pillars:"

"• money will be assigned a prominent role. This role will be signalled by the announcement of a quantitative reference value for the growth of a broad monetary

\footnotetext{
${ }^{25}$ For reasons explained in Gordon [41], I believe that Akerlof, Dickens and Perry [1] reach a too pessimistic conclusion. On the other hand, their data is from the United States and Canada, and downward nominal wage rigidity may be more relevant in Europe. Orphanides' and Wieland's [57] conclusions are sensitive to assumptions about the size of shocks and the average real interest rate, the latter which is taken to be 1 percent for the United States. If the average real rate is higher in Europe, and the shocks not much larger than in the United States, nonnegative interest rates may be of less consequence in Europe.

${ }^{26}$ Note the possible ambiguity: whereas this quote can be interpreted as indicating $\lambda>0$, the first quote in the subsection can be interpreted as indicating $\lambda=0$.
} 
aggregate. The reference value will be derived in a manner which is consistent withand will serve to achieve - price stability.

Deviations of current monetary growth from the reference value would, under normal circumstances, signal risks to price stability. The concept of a reference value does not imply a commitment to mechanistically correct deviations over the short term.

The relationship between actual monetary growth and the pre-announced reference value will be regularly and thoroughly analysed by the Governing Council of the ECB; the result of this analysis and its impact on monetary policy decisions will be explained to the public. The precise definition of the reference aggregate and the specific value of the quantitative reference value for monetary growth will be announced by the Governing Council of the ECB in December 1998;

- in parallel with the analysis of monetary growth in relation to the reference value, a broadly-based assessment of the outlook for price developments and the risks to price stability in the euro area will play a major role in the ESCB's strategy. This assessment will be made using a wide range of economic and financial variables as indicators for future price developments."

The statement that "[t]he concept reference value does not imply a commitment to mechanistically correct deviations over the short term" must be interpreted as the reference value not being an intermediate target for money growth. Indeed, the Eurosystem has rejected monetary targeting, on the grounds that the relationship between money and prices may not be sufficiently stable, and that it is not clear that the monetary aggregates with the most stable relationship is sufficiently controllable in the short run. As Issing [47] summarizes:

"In these circumstances, relying on a pure monetary targeting strategy would constitute an unrealistic, and therefore misguided, commitment."

Instead, the Eurosystem plans to use money growth as an indicator of "risks to price stability," such that "[d]eviations of current money growth from the reference value would, under normal circumstances, signal risks to price stability."

The text clearly emphasizes the role of the relationship between actual monetary growth and the announced reference value in the communication with the general public. The text is silent on whether inflation forecasts will be published or not; at the press conference, Duisenberg reportedly stated that inflation forecasts will not be published (Financial Times [36]). About a month later, Duisenberg [26] stated in no uncertain terms that inflation forecasts would not be published. The reasons given were that

“... publishing an inflation forecast would obscure rather than clarify what the Governing Council is actually doing. The public would be presented with a single number intended to summarise a thorough and comprehensive analysis of a wide range of 
indicator variables. However, such a summary would inevitably be simplistic. Moreover, because publishing a single inflation forecast would be likely to suggest that monetary policy reacts mechanistically to this forecast, publication might mislead the public and therefore run counter to the principle of clarity."

The reasons given are somewhat surprising, since it is common knowledge that the inflationtargeting central banks that publish inflation forecasts provide considerable discussion and explanation of the assumptions, data and analyses behind the inflation forecasts, including a discussion of the uncertainties involved. Both Bank of England and Sveriges Riksbank publish uncertainty bands and fan charts. Reserve Bank of New Zealand provides extensive verbal discussion of the uncertainty involved. No inflation-targeting central bank publishes a single number and no explanation of assumptions, data and analysis. What they publish are indeed examples of "a broadly-based assessment of the outlook for price developments and the risks to price stability."

The quantitative reference value for monetary growth was announced on December 1, namely 4.5 percent for M3. This was calculated from an estimated trend growth of real GDP in the euro area, $2-2.5$ percent per year, an assumed trend decline in velocity of $0.5-1$ percent per year, and the definition of price stability, "below $2 \%$." Adding the midpoint of the intervals for GDP and velocity gives 3 percent. To get to 4.5 percent, "below $2 \%$ " must be 1.5 percent. Hence, the inflation target of the Eurosystem seems to be 1.5 percent, and if that is the midpoint of an interval, that interval must be interpreted as 1-2 percent.

The prominent role for money seems very problematic. The fact is that the deviation between monetary growth and any reference value is a very poor indicator of "risks to price stability," that is, inflationary or deflationary pressure. This is the case under normal circumstances, even absent any velocity shocks, as is shown below. A monetary policy that effectively maintains low and stable inflation must instead rely on inflation forecasts. This is easily illustrated in a simple model of a closed economy.

\subsection{The simplest model of the monetary transmission mechanism}

The role of inflation forecasts and money growth as indicators in a policy aimed at maintaining low and stable inflation is easily shown in a very simple model, which nevertheless matches some stylized facts. ${ }^{27}$ Thus, we can use this model to test the soundness of the monetary policy

\footnotetext{
${ }^{27}$ This model is a variant of the one used in Svensson [68] and [69], and is further discussed in those papers. The model is estimated for the United States in Rudebusch and Svensson [62], and estimated and used for the EMU in Peersman and Smets [58], Gerlach and Smets [40] and Taylor [78].
} 
strategy of the Eurosystem. If its strategy is deficient in this simple model, it is likely to be even more deficient in a more complicated model with more forward-looking elements and, indeed, in the real world..$^{28}$

Consider an aggregate model for the EMU as a whole. Let EMU-wide aggregate demand be given by the equation

$$
x_{t+1}=\beta_{y} x_{t}-\beta_{r}\left(i_{t}-\pi_{t+1 \mid t}-\bar{r}\right)+\beta_{z} z_{t}+\eta_{t+1},
$$

where aggregate demand is expressed in terms of the EMU-wide output gap, so that $x_{t}$ is the output gap in year $t$, given by

$$
x_{t} \equiv y_{t}-y_{t}^{n}
$$

where $y_{t}$ is EMU-wide (log) output and $y_{t}^{n}$ is the EMU-wide (log) potential output in year $t$. The ECB's instrument, $i_{t}$, is a short nominal interest rate (the repurchase rate), $\pi_{t}$ is MUICPinflation between year $t-1$ and $t, z_{t}$ is an exogenous variable (easily generalized to a vector of exogenous variables), and $\eta_{t+1}$ is an iid mean-zero shock to the output gap that is not known in year $t$. Inflation expectations $\pi_{t+1 \mid t}$ are given by $\mathrm{E}_{t} \pi_{t+1}$, the expectation of $\pi_{t+1}$ conditional on information available in year $t$. The coefficients $\beta_{y}$ and $\beta_{r}$ are positive, $\beta_{y}<1$, and the constant $\bar{r}$ is the average real interest rate, that is, the natural real interest rate.

Let aggregate supply be given by the equation

$$
\pi_{t+1}=\pi_{t}+\alpha_{x} x_{t}+\alpha_{z} z_{t}+\varepsilon_{t+1}
$$

where the coefficient $\alpha_{x}$ is positive and $\varepsilon_{t+1}$ is an iid mean-zero shock.

Thus, the central bank can affect the output gap with a one-year lag, and inflation with a two-year lag. In year $t, \pi_{t}, y_{t}$ and $\pi_{t+1 \mid t}$ are predetermined and cannot be affected by monetary policy. $^{29}$

Suppose the demand for a broad EMU-wide monetary aggregate, like M3, is given by a standard money-demand equation,

$$
m_{t+1}-p_{t+1}=\kappa_{y} y_{t}-\kappa_{i} i_{t}+\kappa_{z} z_{t}+\nu_{t+1},
$$

\footnotetext{
${ }^{28}$ The model abstracts from open-economy issues. It agrees with conventional wisdom on the monetary transmission mechanism, in that inflation is determined by aggregate demand and aggregate supply, without any explicit role for money. Money is introduced via a money-demand function and hence, determined by demand. See Svensson [71] and [70] for further discussion of these points and for extensions to open economies and to forward-looking behavior.

${ }^{29}$ The choice of a year as a period allows pedagogical simplifications. Rudebusch and Svensson [62] and the other empirical papers referred to in footnote 27 use a quarterly variant of the model.
} 
where the coefficients $\kappa_{y}$ and $\kappa_{i}$ are positive and $\nu_{t+1}$ is an iid mean-zero shock. Thus real money demand is supposed to depend on the nominal interest rate, output and the exogenous variable, with a lag. Some adjustment lag is realistic and consistent with the central bank having imperfect control over the monetary aggregate. Arguably, a one-year adjustment lag is too long. Therefore, I will also consider the variant when there is no adjustment lag in money demand. Note that money demand is, realistically, a function of output rather than of the output gap.

Finally, suppose that the central bank has an intertemporal loss function in year $t$ given by (1) with the periodloss function (2). For simplicity, consider the case of strict inflation targeting, $\lambda=0$, so that the period loss function is

$$
L_{t}=\frac{1}{2}\left(\pi_{t}-\pi^{*}\right)^{2} .
$$

It is easy to see that the first-order condition for minimizing the intertemporal loss function (1), subject to (4) and (6), simplifies to

$$
\pi_{t+2 \mid t}=\pi^{*}
$$

where $\pi_{t+2 \mid t}=\mathrm{E}_{t} \pi_{t+2}$ denotes the two-year-ahead conditional inflation forecast, given by

$$
\begin{aligned}
\pi_{t+2 \mid t} & =\pi_{t+1 \mid t}+\alpha_{x} x_{t+1 \mid t}+\alpha_{z} z_{t+1 \mid t} \\
& =\pi_{t+1 \mid t}+\alpha_{x} \beta_{y} x_{t}+\alpha_{x} \beta_{z} z_{t}+\alpha_{z} z_{t+1 \mid t}-\alpha_{x} \beta_{r}\left(i_{t}-\pi_{t+1 \mid t}-\bar{r}\right)
\end{aligned}
$$

where I have used (6) and (4). ${ }^{30} 31$

Combining (9) and (10) and solving for the instrument level result in the optimal reaction function under strict inflation targeting,

$$
i_{t}=\bar{r}+\pi^{*}+\frac{1+\alpha_{x} \beta_{r}}{\alpha_{x} \beta_{r}}\left(\pi_{t+1 \mid t}-\pi^{*}\right)+\frac{\beta_{y}}{\beta_{r}} x_{t}+\frac{\beta_{z}}{\beta_{r}} z_{t}+\frac{\alpha_{z}}{\alpha_{x} \beta_{r}} z_{t+1 \mid t} .
$$

Thus, the optimal policy can be described as using the relevant current information about the state of the economy to construct a conditional two-year-ahead inflation forecast, and then setting the instrument such that the two-year-ahead conditional inflation forecast equals the inflation target. Such policy will result in the instrument being a function of the inflation target and the information about the state of the economy that is relevant for constructing the

\footnotetext{
${ }^{30}$ In this annual model with a two-year control lag for inflation, strict inflation targeting corresponds to the two-year-ahead conditional inflation forecast equal to the inflation target. In a quarterly model, with a control lag for inflation equal to a few quarters (less than eight), an eight-quarter-ahead conditional inflation forecast equal to the inflation target can be interpreted as an approximation of a first-order condition for flexible inflation targeting, since eight quarters is then longer than the minimum control lag.

${ }^{31}$ The analysis is easily adapted to the case of flexible inflation targeting, $\lambda>0$. As shown in Svensson [68], the first-order condition (9) is then replaced by $\pi_{t+2 \mid t}-\pi^{*}=c(\lambda)\left(\pi_{t+1 \mid t}-\pi^{*}\right)$, where $c(\lambda)$ is an increasing function of $\lambda$, with $0 \leq c(\lambda)<1, c(0)=0$ and $c(\lambda) \rightarrow 1$ for $\lambda \rightarrow \infty$.
} 
conditional inflation forecast. In this model, the relevant information is the predetermined oneyear-ahead inflation forecast, $\pi_{t+1 \mid t}$, the output gap, $x_{t}$, and the current and forecasted values of the exogenous variable, $z_{t}$ and $z_{t+1 \mid t} \cdot{ }^{32}$ The predetermined one-year-ahead inflation forecast is by (6) constructed from current inflation, the current output gap, and the current exogenous variable, according to

$$
\pi_{t+1 \mid t}=\pi_{t}+\alpha_{x} x_{t}+\alpha_{z} z_{t}
$$

The conditional two-year-ahead inflation forecast in this example corresponds to the "broadly based assessment of the outlook for future price development" mentioned in the Eurosystem's October 13 announcement of the strategy.

\subsection{An optimal indicator of "risks to price stability"}

What is the best indicator of "risks to price stability," that is, inflationary or deflationary pressure, in this setup? ${ }^{33}$ The most intuitive indicator is obviously one that signals by how much the inflation target is likely to be missed in case policy is not adjusted. Such an indicator would also signal in what direction and by how much the instrument should be adjusted to restore price stability. An obvious candidate is the deviation between an appropriately defined inflation forecast and the inflation target. For this purpose, define $\Pi_{t+2 \mid t}(i)$ as the two-yearahead inflation forecast conditional upon a given interest rate $i$ and the state of the economy in year $t$ (that is, $\pi_{t+1 \mid t}, x_{t}, z_{t}$ (or, by $(12), \pi_{t}, x_{t}, z_{t}$ ) and the forecast $z_{t+1 \mid t}$ ), that is,

$$
\Pi_{t+2 \mid t}(i) \equiv \pi_{t+1 \mid t}+\alpha_{x} \beta_{y} x_{t}+\alpha_{x} \beta_{z} z_{t}+\alpha_{z} z_{t+1 \mid t}-\alpha_{x} \beta_{r}\left(i-\pi_{t+1 \mid t}-\bar{r}\right) .
$$

Then, call $\Pi_{t+2 \mid t}\left(i_{t-1}\right)$ the two-year-ahead conditional "unchanged-interest-rate" inflation forecast, that is, the conditional inflation forecast when the interest rate is unchanged from last year, $\Delta i_{t} \equiv i_{t}-i_{t-1}=0$. Finally, define the "inflation-forecast" indicator $I_{t}^{\pi}$ as the deviation of the conditional unchanged-interest-rate inflation forecast from the inflation target,

$$
I_{t}^{\pi} \equiv \Pi_{t+2 \mid t}\left(i_{t-1}\right)-\pi^{*}
$$

${ }^{32}$ Thus, we see that the reaction function includes the output gap as an argument, since it affects the two-year conditional inflation forecast, even if the output gap does not enter the loss function.

${ }^{33}$ Note that by indicator, we mean a variable that conveys useful information to the central bank, for instance, about the required direction of change of the instrument. This meaning of indicators may seem to be different from that used in Brunner and Meltzer [12] and [13] (BM): "The indicator problem of monetary policy is the problem of constructing a scale that is invariant up to a monotone transformation and that provides a logical foundation for statements comparing the thrust of monetary policy" ([13], p. 2). (Friedman [38] expresses doubts about the usefulness of the BM indicator.) If interpreted as monetary policy's impact on the real economy, in the simple model used here, a BM indicator might be the difference between the short real interest rate and the natural real interest rate, $i_{t}-\pi_{t+1 \mid t}-\bar{r}$. However, if the BM indicator is interpreted as indicating the deviation of a target variable from the target level, the inflation-forecast indicator presented below is a BM indicator. 
This is, arguably, a very appropriate indicator of inflationary or deflationary pressure. It indicates the extent to which inflation two-year-ahead is likely to exceed the inflation target in case monetary policy is "unchanged," in the sense that the instrument is kept unchanged. Therefore, it indicates whether the instrument needs to be adjusted in order to minimize the loss function (8).

Furthermore, $I_{t}^{\pi}$ indicates both the direction and the magnitude of the optimal change in the instrument. We have

$$
\Pi_{t+2 \mid t}\left(i_{t}\right)-\Pi_{t+2 \mid t}\left(i_{t-1}\right)=\frac{\partial \Pi_{t+2 \mid t}\left(i_{t-1}\right)}{\partial i} \Delta i_{t}
$$

Combining this with (9), we get the optimal adjustment of the instrument,

$$
\Delta i_{t}=\frac{1}{-\frac{\partial \Pi_{t+2 \mid t}\left(i_{t-1}\right)}{\partial i}} I_{t}^{\pi}=\frac{1}{\alpha_{x} \beta_{r}} I_{t}^{\pi}
$$

where I have used (13) and (14). Thus, the required change in the instrument is proportional to the inflation-forecast indicator, more precisely the inflation-forecast indicator divided by the negative of the policy-multiplier, $-\partial \Pi_{t+2 \mid t}\left(i_{t-1}\right) / \partial i=\alpha_{x} \beta_{r}{ }^{34}$

Using (13), the inflation-forecast indicator can be expanded as

$$
I_{t}^{\pi}=\pi_{t+1 \mid t}-\pi^{*}+\alpha_{x} \beta_{y} x_{t}+\alpha_{x} \beta_{z} z_{t}+\alpha_{z} z_{t+1 \mid t}-\alpha_{x} \beta_{r}\left(i_{t-1}-\pi_{t+1 \mid t}-\bar{r}\right) .
$$

It is a particular way of aggregating the information about the state of the economy, and hence, a particular linear combination of $\pi_{t+1 \mid t}, x_{t}, z_{t}$ and $z_{t+1 \mid t}$. Due to (12), it can equivalently be written as a linear combination of $\pi_{t}, x_{t}, z_{t}$ and $z_{t+1 \mid t}$,

$$
I_{t}^{\pi}=\pi_{t}-\pi^{*}+\alpha_{x}\left(1+\beta_{y}\right) x_{t}+\left(\alpha_{z}+\alpha_{x} \beta_{z}\right) z_{t}+\alpha_{z} z_{t+1 \mid t}-\alpha_{x} \beta_{r}\left(i_{t-1}-\pi_{t+1 \mid t}-\bar{r}\right) .
$$

\subsection{The inadequacy a money-growth indicator}

How appropriate is a money-growth indicator of the kind suggested by the Eurosystem? First, we need to derive a reference value "in a manner which is consistent with... price stability" (let me leave the question whether the reference value also "will serve to achieve... price stability" open for a while). By (7), money growth is given by

$$
\Delta m_{t+1}=\pi_{t+1}+\kappa_{y} \Delta y_{t}-\kappa_{i} \Delta i_{t}+\kappa_{z} \Delta z_{t}+\Delta \nu_{t+1} .
$$

\footnotetext{
${ }^{34}$ The analogue of (16) under Brainard-type [9] parameter uncertainty is easily derived, cf. Svensson [69].
} 
Let the reference value, $\Delta m^{*}$, be the average money-growth consistent with average inflation equal to the inflation target. ${ }^{35}$ Average money growth is given by the unconditional expectation

$$
\mathrm{E}\left[\Delta m_{t+1}\right]=\mathrm{E}\left[\pi_{t+1}+\kappa_{y} \Delta y_{t}-\kappa_{i} \Delta i_{t}+\Delta \nu_{t+1}\right]=\mathrm{E}\left[\pi_{t}\right]+\kappa_{y} \mathrm{E}\left[\Delta y_{t}\right],
$$

where I have used that average inflation is bounded and that the unconditional mean of the exogenous variable is zero, which implies $\mathrm{E}\left[\Delta z_{t}\right]=\mathrm{E}\left[\Delta i_{t}\right]=0$. Furthermore, consistency with the inflation target requires

$$
\mathrm{E}\left[\pi_{t}\right]=\pi^{*}
$$

Then the reference value that is "consistent with price stability" is given by

$$
\Delta m^{*} \equiv \pi^{*}+\kappa_{y} \mathrm{E}\left[\Delta y_{t}\right]
$$

Note that this reference value is consistent with the Eurosystem's derivation. Identify predicted trend growth in output with average output growth, $\mathrm{E}\left[\Delta y_{t}\right] .{ }^{36}$ By (7), (log) velocity is given by

$$
v_{t+1} \equiv p_{t+1}+y_{t+1}-m_{t+1}=y_{t+1}-\kappa_{y} y_{t}+\kappa_{i} i_{t}-\kappa_{z} z_{t}-\nu_{t+1} .
$$

Then the velocity trend is

$$
\mathrm{E}\left[\Delta v_{t+1}\right]=\mathrm{E}\left[\Delta y_{t+1}-\kappa_{y} \Delta y_{t}+\kappa_{i} \Delta i_{t}-\kappa_{z} \Delta z_{t}-\Delta \nu_{t+1}\right]=\left(1-\kappa_{y}\right) \mathrm{E}\left[\Delta y_{t}\right]
$$

Thus, the reference value is

$$
\pi^{*}+\mathrm{E}\left[\Delta y_{t}\right]-\mathrm{E}\left[\Delta v_{t}\right]=\pi^{*}+\kappa_{y} \mathrm{E}\left[\Delta y_{t}\right]
$$

which agrees with (22).

The Eurosystem suggests that "[d]eviations of current monetary growth from the reference value would, under normal circumstances, signal risks to price stability.” Let us examine whether this is the case. Define the money-growth indicator

$$
I_{t}^{m} \equiv \Delta m_{t}-\Delta m^{*}
$$

By (19) and (22) we get

$$
I_{t}^{m}=\left(\pi_{t}-\pi^{*}\right)+\kappa_{y}\left(\Delta y_{t-1}-\mathrm{E}\left[\Delta y_{t}\right]\right)-\kappa_{i} \Delta i_{t-1}+\kappa_{z} \Delta z_{t-1}+\Delta \nu_{t} .
$$

\footnotetext{
${ }^{35}$ This is an unconditional reference value, independent of the current state of the economy. Se appendix B of the conference version of this paper for a discussion of a conditional reference value that can serve as a complex (and nontransparent) frequently adjusted money-growth target, the fulfillment of which is equivalent to strict inflation targeting.

${ }^{36}$ That is, I assume that the unconditional and the conditional forecast of the growth of potential output are equal, $\mathrm{E}_{t} \Delta y_{t+1}^{n}=\mathrm{E}\left[\Delta y_{t}^{n}\right]$, and use $\mathrm{E}\left[\Delta y_{t}\right]=\mathrm{E}\left[\Delta y_{t}^{n}\right]$.
} 
It is not clear what this money-growth indicator signals. Above all, it is not clear why it would signal "risks to price stability" or inflationary or deflationary pressure, except that the first term on the right side of (27) is the current deviation of inflation from the inflation target. However, this term is quite trivial and does not need a monetary indicator to be observed. Besides, it only contains very partial information; it is only one of several components of the optimal inflationforecast indicator $I_{t}^{\pi}$, cf. (18). The money-growth indicator can be of either sign, independent of the sign of $I_{t}^{\pi}$ or whether $I_{t}^{\pi}$ is zero and no change in the instrument is required. Thus, the money-growth indicator $I_{t}^{m}$ does generally not indicate in which direction the instrument should be changed. It mainly seems to be a noisy indicator of $\pi_{t}-\pi^{*}$.

Note that the money-growth indicator would still be inferior, if money had a more direct role in the transmission mechanism (6) and (4). Assume, for instance, that there is a realbalance effect on aggregate demand, such that (4) has an additional term $\beta_{m}\left(m_{t}-p_{t}\right)$ on the right side. This implies that $(\log )$ real balances, $m_{t}-p_{t}$, is an additional state variable. Then the optimal reaction function (11), under strict inflation targeting, would have the additional term $\frac{\beta_{m}}{\beta_{r}}\left(m_{t}-p_{t}\right)$ on the right side. Furthermore, the two-year-ahead inflation forecast (13) and the inflation-forecast indicators (17) and (18) would have the additional term $\alpha_{x} \beta_{m}\left(m_{t}-p_{t}\right)$ on the right side. Real balances become one of the inputs in the inflation forecast, but the money-growth indicator (26) would be equally inappropriate as an indicator of risks to price stability.

\subsubsection{Strict money-growth targeting}

If the money-growth indicator were meaningful, targeting money-growth, in the sense of minimizing the deviations of money growth from the reference value (that is, strict money-growth targeting), should not be an unreasonable policy. The interest rate should then be set so that the one-year-ahead conditional forecast of the money-growth indicator equals zero,

$$
I_{t+1 \mid t}^{m}=0 .
$$

Solving for the corresponding change in the interest rate gives

$$
\Delta i_{t}=\frac{1}{\kappa_{i}}\left(\pi_{t+1 \mid t}-\pi^{*}\right)+\frac{\kappa_{y}}{\kappa_{i}}\left(\Delta y_{t}-\mathrm{E}\left[\Delta y_{t}\right]\right)+\frac{\kappa_{z}}{\kappa_{i}} \Delta z_{t}-\frac{1}{\kappa_{i}} \nu_{t} .
$$

Let us compare this to the optimal interest rate adjustment according to (16) and (17),

$$
\Delta i_{t}=\frac{1}{\alpha_{x} \beta_{r}}\left(\pi_{t+1 \mid t}-\pi^{*}\right)+\frac{\beta_{y}}{\beta_{r}} x_{t}+\frac{\beta_{z}}{\beta_{r}} z_{t}+\frac{\alpha_{z}}{\alpha_{x} \beta_{r}} z_{t+1 \mid t}-\left(i_{t-1}-\pi_{t+1 \mid t}-\bar{r}\right) .
$$


It is clear that these two reaction functions are quite different, and that setting $I_{t+1 \mid t}^{m}$ equal to zero would normally create considerable variability in inflation, since (30) minimizes inflation variability. Note that this would be true even if velocity shocks were zero, $\nu_{t} \equiv 0$. Not only are the coefficients different, the reaction functions also involve different variables, above-trend output growth for monetary targeting $\left(\Delta y_{t}-\mathrm{E}\left[\Delta y_{t}\right]\right)$ and the output gap for strict inflation targeting $\left(x_{t}\right)$. Furthermore, they are of different forms, in the sense that (29) is a difference form whereas (30) is basically a level form, see (11). Rudebusch and Svensson [63] confirm empirically that (29) is a very inefficient reaction function. ${ }^{37}$

Thus, as Taylor [76] has observed, money-growth targeting implies a particular reaction function. However, in contrast to what is indicated by Taylor himself, this reaction function may be quite different from the reaction function with which he is associated and promotes; and even more so when more realistic demand functions are considered, see below.

A reaction function like (29) may seem attractive for the simple reason that it requires minimum information, in the sense that only parameters of the money demand function is needed (although those parameters may not be easily estimated at the onset of EMU). However, this does not change the fact that this minimum information seems to be the wrong minimum information; it is simply inadequate to efficiently stabilize inflation. One aspect is that a lower interest rate sensitivity of money demand, a lower coefficient $\kappa_{i}$, would, everything else equal, require larger interest rate changes. The magnitude of $\kappa_{i}$ is, of course, related to the controllability of money demand; Cabrero, Escrivá, Muñoz and Peñalosa [19] show that current estimates of potential aggregate money-demand functions for the EMU indicate that monetary aggregates would be considerably less controllable in the EMU than in Germany, even if the parameters were stable, and hence require larger interest changes to fulfill a given monetary target.

\subsubsection{Other money-demand formulations}

Furthermore, this inadequacy of monetary targeting is not due to the assumed adjustment lag for money demand. In order to stack the cards in favor of the money-growth indicator, assume that money-growth adjusts without a lag, so that

$$
\Delta m_{t}=\pi_{t}+\kappa_{y} \Delta y_{t}-\kappa_{i} \Delta i_{t}+\kappa_{z} \Delta z_{t}+\Delta \nu_{t}
$$

\footnotetext{
${ }^{37}$ Furthermore, a real-balance effect on aggregate demand would only add the term $\frac{\beta_{m}}{\beta_{r}}\left(m_{t}-p_{t}\right)$ on the right side of (30) and not make (29) more attractive.
} 
The money-growth indicator would then be

$$
I_{t}^{m}=\left(\pi_{t}-\pi^{*}\right)+\kappa_{y}\left(\Delta y_{t}-\mathrm{E}\left[\Delta y_{t}\right]\right)-\kappa_{i} \Delta i_{t}+\kappa_{z} \Delta z_{t}+\Delta \nu_{t} .
$$

It is now directly affected by the current instrument and can hence not be observed before the instrument setting. It does not seem more informative about inflationary or deflationary pressure.

Solving for the interest rate change that makes the current money-growth indicator equal to zero gives

$$
\Delta i_{t}=\frac{1}{\kappa_{i}}\left(\pi_{t}-\pi^{*}\right)+\frac{\kappa_{y}}{\kappa_{i}}\left(\Delta y_{t}-\mathrm{E}\left[\Delta y_{t}\right]\right)+\frac{\kappa_{z}}{\kappa_{i}} \Delta z_{t}+\frac{1}{\kappa_{i}} \Delta v_{t} .
$$

This is similar to (29), except that current inflation is substituted for the one-year-ahead inflation forecast and that the velocity term is different. This reaction function is still inadequate, even in the absence of velocity shocks.

Considering a more realistic money-demand function does not make the money-growth indicator or the reaction function corresponding to strict monetary targeting more attractive. This is demonstrated in appendix $\mathrm{C}$ of the conference version of this paper, which considers a typical empirical quarterly money-growth demand equation for western German M3 estimated by Gerlach [39]. Other similar money-demand equations, for instance those estimated and discussed in Issing and Tödter [48] or Wolters, Teräsvirta and Lütkepohl [81], would give similar results. Rudebusch and Svensson [63] confirm the inefficiency of money-growth targeting for the United States and Europe, with empirical money-demand functions.

A general way of understanding the inadequacy of money-growth indicators and moneygrowth targeting is to recall the tradeoff between inflation variability and money-growth variability, illustrated in figure 1. Strict inflation targeting minimizes inflation variability around the inflation target, which leads to substantial money-growth variability. Strict money-growth targeting minimizes money-growth variability around the money-growth target, which can be chosen such that average inflation equals the inflation target, but money-growth targeting leads to considerable inflation variability around the inflation target. This would be the case even if money-demand shocks were zero, for the simple reason that the reaction function that stabilizes money growth is manifestedly different from the reaction function that minimizes inflation variability (or minimizes a weighted average of inflation variability and output-gap variability, cf. figure 2). 


\subsection{Summary}

There are many sensible aspects of the Eurosystem's October 13 announcement, for instance, the choice of the MUICP (which does not include interest-rate costs) as the main index, the focus on the euro area as a whole, the warning about unavoidable and uncontrollable shortterm volatility of prices, the emphasis on the medium term, and the rejection of money-growth targeting. Still, the announcement and the strategy proposed have a number of conspicuous deficiencies.

First, the statement that the Eurosystem "will focus strictly on [the price stability] objective" is somewhat at variance with the medium-term emphasis, since the medium-term horizon can be rationalized by a concern about output-gap variability and, hence, correspond to flexible inflation targeting and a loss function like (2). Second, the strategy gives a prominent role to an essentially useless monetary reference value and monetary indicator, in analysis and communication. Third, although the strategy assigns a major role to an inflation forecast, and this forecast will, in practice, be crucial for policy decisions, the Eurosystem (for no good reasons; cf. the quote from Duisenberg [26] above) does not intend to focus communication on this forecast, but instead intends to keep it secret and therefore completely nontransparent. ${ }^{38}$

Thus, as many commentators have noticed, the Eurosystem seems to have opted for a fair amount of ambiguity, relatively little transparency and considerable discretion. What could be the explanation for this choice? Potential explanations are a desire to maximize continuity with the Bundesbank and a general desire to maximize independence and discretion, and a belief that the latter is best achieved by avoiding transparency and accountability.

What could motivate a desire for a continuity with Bundesbank? Two possibilities are that (1) the Eurosystem, thereby, hopes to inherit some credibility from the Bundesbank and (2) the Eurosystem does not want to disappoint the German public.

But why would continuity with the Bundesbank be the best way of gaining credibility? Bundesbank's credibility seems to depend on its inflation record and not on its monetary targeting record. Given the many misses of the monetary targets, it appears that Bundesbank's credibility is in spite of the monetary-targeting framework, not thanks to it. It seems that Bundesbank's inflation record has brought respectability and (inflation-)credibility to monetary targeting rather than the other way around. Monetary targeting, measured as the frequency

\footnotetext{
${ }^{38}$ Issing [45] has defended the transparency and accountability of the Eurosystem with reference to the frequence and volume of information the Eurosystem intends to make public; content, and not frequency and volume, is the relevant aspect, though.
} 
of hits, may not have been more successful in Germany than in many other countries where monetary targeting has eventually been officially abandoned. This is certainly consistent with the conclusion above that Bundesbank, in effect, has pursued inflation targeting rather than monetary targeting.

If the above argument is correct, alleged monetary targeting need not give the Eurosystem any credibility per se. Instead, it must maintain any initial credibility, and gain any new credibility, by showing a good track record for inflation. The absence of an initial track record together with an ambiguous and intellectually weak strategy with irrelevant money-growth reference values and ad hoc explanations for unavoidable misses is unlikely to enhance credibility and more likely to diminish it.

Why would it be important not to disappoint the German public? It seems that the German public has been led to believe that monetary targeting is an essential part of Bundesbank's impressive inflation record. Furthermore, it appears that the German public's (still quite reluctant) acceptance of Germany joining the EMU is, to a large extent, conditional on the understanding that the Eurosystem will behave very similar to the Bundesbank. Announcing a strategy deviating too much from Bundesbank's official strategy would then be politically dangerous and endanger the Eurosystem's legitimacy with the German public. The Eurosystem might already have done as much as it dares, by rejecting monetary targeting and even daring to mention the major role of an inflation forecast?

On the other hand, in the new political situation in Germany, with the new government being doubtful about Bundesbank and Eurosystem monetary policy, too much loyalty to Bundesbank's official framework may backfire. More transparent and direct communication, together with an intellectually stronger strategy, might be more effective, as further discussed in sections 5 and 6 .

A desire to maximize independence and discretion by minimizing transparency and accountability is probably natural to any bureaucracy. However, this way of maximizing independence may be quite ineffective, since the political legitimacy of the Eurosystem may be weakened from a perceived lack of transparency and accountability. Furthermore, a lack of transparency makes it more difficult to rebut criticism. Whereas pragmatic monetary targeting may have been very effective for achieving and maintaining Bundesbank's independence in the 1970s, see von Hagen [80], the political situation for the Eurosystem is quite different and there is no reason why this should be effective now. As argued in section 6, transparency and accountability may be more effective for safeguarding the Eurosystem's independence and maintaining monetary stability in 
the EMU in the long run.

\section{Achieving price stability: Targets and the framework for pol- icy decisions}

This section tries to specify the most efficient way for the Eurosystem of fulfilling its objectives according to the Maastricht Treaty. The Eurosystem basically needs to translate the objectives into operational targets, and then find the framework for policy decisions that best achieves those operational targets.

\subsection{Specifying the targets}

The Eurosystem's operational definition of price stability has been interpreted above as a target range for the MUICP-inflation between 1 and 2 percent, with the interval's midpoint, $\pi^{*}=1.5$ percent, as the inflation target. Alternatively, the definition might be interpreted as a target range of 0-2 percent, with the midpoint and inflation target equal to 1 percent. To ensure transparency of the definition, the Eurosystem would need to remove the ambiguity about the lower bound and the midpoint. Furthermore, the Eurosystem's statement about the medium term would need to be operational. In line with other inflation-targeting central banks, the appropriate horizon for the inflation forecast to equal the inflation targets may be in the $1.5-2.5$ years range, depending upon the nature of the disturbance and the initial deviation from the target. There will be short-term volatility of inflation, part of which the Eurosystem cannot control due to the unavoidable lags in the effects of monetary policy, part of which it should not attempt to control, since that would require drastic instrument adjustments likely to cause undue volatility of economic variables other than inflation. This corresponds to flexible inflation targeting, and a loss function like (2) with $\lambda>0$.

After a few years, when some experience has been gained and the policy regime can be evaluated, the Eurosystem may want to reconsider its definition of price stability. In particular, with more experience of inflation targeting in the EMU and in inflation-targeting countries outside the EMU (perhaps after 5 or 10 years) the Eurosystem may want to consider price-level targeting rather than inflation targeting. It is often forgotten that inflation targeting implies base drift for the price level and hence a nonstationary price level. To call this price stability is indeed misleading. True price stability would require a stationary or at least a trend-stationary 


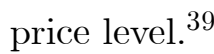

\subsection{The framework for policy decisions: How to set the repurchase rate}

With an intertemporal loss function given by (1) and (2), the operational problem of the Eurosystem is formally, first, to find a feasible set $Y^{t}$ of conditional forecasts of EMU inflation, $\pi^{t} \equiv\left(\pi_{t}, \pi_{t+1 \mid t}, \pi_{t+2 \mid t}, \ldots\right)$, the EMU output gap, $x^{t} \equiv\left(x_{t}, x_{t+1 \mid t}, \ldots\right)$ and interest rate paths $i^{t} \equiv\left(i_{t}, i_{t+1 \mid t}, \ldots\right)$, and, second, to choose $\left\{\pi^{t}, x^{t}, i^{t}\right\} \in Y^{t}$ so as to minimize (1) with $L_{t}$ given by (2). The first element of the instrument path, $i_{t}$, is then the appropriate current instrument setting. This is equivalent to considering the conditional forecasts $\pi^{t}$ and $x^{t}$ as intermediate targets.

For this purpose, the Eurosystem must be able to calculate EMU-wide conditional inflation and output-gap forecasts. The Eurosystem must be able to calculate such forecasts for unchanged interest rates, for arbitrarily given interest rate paths, and for arbitrary reaction functions. It must then also estimate and determine policy multipliers, like $\frac{\partial}{\partial i_{t}} \pi_{t+T \mid t}$ and $\frac{\partial}{\partial i_{t}} x_{t+T \mid t}$. It must determine the essential information input needed in these forecasts, and collect the appropriate data.

The Eurosystem must also be able to incorporate both model and extra-model information, that is, different kinds of informal information, and to make judgemental adjustments. By its nature, the inflation- and output-gap-forecasting framework actually enforces a certain amount of discipline on judgemental adjustments. In order to motivate why a particular piece of information should influence the current instrument setting, a convincing case must be presented why this piece of information will affect the inflation forecast or the output-gap forecast at a horizon where monetary policy can have some effect. Without such a case, there is no reason for adjusting the instrument. Thus, "information needs to be filtered through the forecasts," in order to have any effect on the instrument. ${ }^{40}$

Several inflation-targeting central banks have translated this framework into a condition of the form

$$
\pi_{t+T \mid t}=\pi^{*},
$$

where the horizon $T$ is a function of current information. That is, an approximate first-order condition for a minimum of the loss function is that the conditional inflation forecast for the

\footnotetext{
${ }^{39}$ Svensson [72] and [73] provides some discussion of price-level targeting and references to the literature.

40 See Svensson [67] and [70] for further discussion. Svensson [73] discusses distribution forecast target as a possible extension of mean forecast targeting, in order to incorporate model uncertainty and nonlinearities which imply that certainty-equivalence no longer holds.
} 
planned instrument path coincides with the inflation target for an appropriate horizon, where the horizon may depend on the state of the economy. ${ }^{41}$ As discussed above in section 2 , this may allow a crucial role for the inflation-forecast indicator

$$
I_{t}^{\pi} \equiv \Pi_{t+T \mid t}\left(i_{t-1}\right)-\pi^{*}
$$

the conditional unchanged-interest-rate inflation forecast for this horizon. Desired changes in the instrument are then indicated by

$$
\Delta i_{t}=\frac{1}{-\frac{\partial \Pi_{t+T \mid t}\left(i_{t-1}\right)}{\partial i_{t}}} I_{t}^{\pi}
$$

\subsection{Aggregated EMU forecasts vs. disaggregated national forecasts}

As the October 13 announcement makes clear, the Eurosystem is concerned about the aggregate HICP for the EMU as a whole, the MUICP. Should the Eurosystem then construct forecasts directly for EMU-wide aggregates, or should these aggregate forecasts be constructed from disaggregated national forecasts? Directly constructing forecasts for the EMU-wide aggregates could have the advantage that some national forecast errors might cancel. On the other hand, if the coefficients in the various aggregate supply and aggregate demand equations differ sufficiently, forecast precision should be higher with disaggregated forecasts. ${ }^{42}$ For instance, MUICP inflation fulfills

$$
\pi_{t}=\sum_{j=1}^{J} \omega_{t}^{\pi j} \pi_{t}^{j}
$$

where $\pi_{t}^{j}$ and $\omega_{t}^{\pi j}$ are HICP inflation in country $j, j=1, \ldots, J$, and the weight of $\pi_{t}^{j}$ in MUICP inflation $\pi_{t}$, respectively. ${ }^{43}$ Then, the $T$-period-ahead conditional inflation forecast is given by

$$
\pi_{t+T \mid t}=\sum_{j} \omega_{t+T \mid t}^{\pi j} \pi_{t+T \mid t}^{j}
$$

(where I disregard the conditional variance between $\omega_{t+T}^{\pi j}$ and $\pi_{t+T}^{j}$ ), and the policy multiplier $\frac{\partial}{\partial i_{t}} \pi_{t+T \mid t}$ will be given by

$$
\frac{\partial \pi_{t+T \mid t}}{\partial i_{t}}=\frac{\partial}{\partial i_{t}} \sum_{j} \omega_{t+T \mid t}^{\pi j} \pi_{t+T \mid t}^{j}=\sum_{j} \omega_{t+T \mid t}^{\pi j} \frac{\partial \pi_{t+T \mid t}^{j}}{\partial i_{t}},
$$

\footnotetext{
${ }^{41}$ For instance, the horizon depends on the initial deviaton of inflation from the inflation target. See Svensson [70] for discussion of alternative approximate first-order conditions.

${ }_{42}$ There is considerable evidence of differences in the transmission mechanism in the EMU Member States, for instance due to differences in the amount or the maturity of indebtedness, see for instance Begg [3], Dornbusch, Favera and Giavazzi [25] and Ramaswamy and Sloek [61].

${ }^{43}$ The country weights are computed every year and reflect the country's share of private final domestic consumption expenditure.
} 
(where I disregard the term $\frac{\partial}{\partial i_{t}} \omega_{t+T \mid t}^{\pi j}$ ). Since the policy multipliers $\frac{\partial}{\partial i_{t}} \pi_{t+T \mid t}^{j}$ for HICP inflation and other monetary policy responses in the different countries are likely to be different, it seems that it will be necessary to start from national conditional forecasts and use nationally disaggregated data. This also allows NCB models and accumulated experiences in forecasting to be taken into account.

Parallel to this, the Eurosystem would, of course, be wise to experiment with aggregate models of the EMU transmission mechanism. Interestingly, Gerlach and Smets [40], Peersman and Smets [58] and Taylor [78] have already estimated and used variants of the Rudebusch and Svensson model [62] for the EMU area, with reasonable and encouraging results.

\subsection{The transmission mechanism with a new common currency}

The irrevocably fixed exchange rates, the new common currency and the new monetary policy regime seem to imply considerable uncertainty about the transmission mechanism of monetary policy and possibly shifts thereof. One issue is whether price- and wage-setting behavior, their inertia and their sensitivity to output gaps and unemployment will change. That is, will aggregate supply relations change? Another issue is whether the sensitivity to interest rate changes of the output gap, unemployment and general real activity to interest rates will change. That is, will aggregate demand relations change?

ECB statements, for instance Issing [46], have warned that the formation of expectations might change in the new circumstances, thereby making old relations unstable. I am not so convinced; it seems that inflation expectations are already rather low and stable in Europe, and absent major mistakes by the Eurosystem, there is no obvious reason why they should change significantly. Furthermore, in the absence of realignments of their central parities, the core countries of the EMU have already effectively had the same monetary policy and similar inflation rates for several years.

The introduction of the Euro will arguably mainly have consequences in the financial sector, by increasing financial integration and financial competition, and by speeding up the rate of financial innovation. On the other hand, considerable financial integration and innovation have already taken place in several EU countries, following the liberalization and deregulation of the financial markets. In some countries, there is already a fair amount of experience of monetary policy under financial innovation.

Given this, the effects on aggregate supply and aggregate demand relations may be less 
dramatic and more gradual, and the construction of reasonably reliable conditional forecasts less difficult, than what appears at first sight.

The most dramatic effects will obviously concern the denomination and substitutability of financial assets and monies. Consequently, the demand for the new currency is likely to be both more unpredictable and potentially more unstable than anything else. It goes without saying that this means that the information content of monetary aggregates becomes even smaller than normal in the short and medium run, perhaps even in the long run.

It may be sobering to recall that the introduction of inflation targeting in the United Kingdom, Sweden and Finland occurred under rather dramatic circumstances. The countries went through dramatic boom-bust experiences, very serious banking and financial-sector crises, and a sudden dramatic shift from a fixed exchange rate to a new monetary policy regime with a floating exchange rate. Furthermore, this occurred in a situation with very low credibility for monetary policy, with high and unstable inflation expectations, much above the announced inflation targets. At least for Sweden (where I am naturally more informed) the central bank's commitment to the fixed exchange rate was so strong that there was no contingency planning. When the krona was floated in November 1992, the new inflation-targeting regime, which was announced in January 1993, had to be conceived from scratch (although, of course, with the benefit of the experiences mainly from New Zealand and Canada). It is not easy to rank difficulties and changes in the transmission mechanism, but it seems to me that the difficulties facing the Eurosystem are still not of the same magnitude as the difficulties that the central banks of United Kingdom, Sweden and Finland were facing. Since those central banks have, nevertheless, managed quite well, the odds for the Eurosystem may be quite good, provided it adopts a similar framework for policy decisions.

In particular, the Eurosystem seems to start in a situation when credibility is high, in the sense that inflation expectations are low and stable. Low and stable inflation expectations are likely to cause both considerable reversion of inflation towards the target and make the impact of the monetary policy instrument larger, thus making the achievement of the Eurosystem's targets correspondingly easier. ${ }^{44}$

\footnotetext{
${ }^{44}$ In order to see this, consider a forward-looking variant of the aggregate supply relation (6),

$$
\pi_{t+1}=\left(1-\alpha_{\pi}\right) \pi_{t+2 \mid t}+\alpha_{\pi} \pi_{t}+\alpha_{x} x_{t}+\varepsilon_{t+1} .
$$
}

where $0<\alpha_{\pi}<1$. With good credibility, the expectation term, $\pi_{t+2 \mid t}$, will be close to the inflation target, $\pi^{*}$. Consequently, there will be an automatic reversion towards the inflation target, which, in itself, makes inflation targeting easier.

With regard to the effect of the instrument, in more elaborate models of the aggregate demand equation than (4) (see Svensson [71] for an example and for references to the literature), aggregate demand is affected by a 


\subsection{The role of monetary aggregates}

What is the role of different monetary aggregates in this framework? A rational role for monetary aggregates simply seems to be one set of indicators among many others, whose usefulness exclusively depend on their performance in predicting inflation. Thus, the issue is simply how useful current money growth is as an input in a two-year conditional inflation forecasts.

Under normal circumstances, the information content of money growth for inflation forecasts in the short and medium term seems to be quite low. In Estrella and Mishkin [28], money has essentially no predictive power beyond lags of inflation and output in forecasting inflation for the United States and Germany. Examining inflation forecasts for the United States, Stock and Watson [65] also find low or no predictive power of money. These empirical findings are consistent with the current conventional wisdom with regard to the transmission mechanism, where money plays no role in the aggregate supply block determining inflation. Only in the long run does a high correlation between money growth and inflation result.

Under the special circumstances of the introduction of a new common currency, the demand for money is likely to be quite unpredictable and possibly very unstable, since the main structural changes are likely to occur in financial markets and banking. Then, the information content of money is, a priori, likely to be even lower than under normal circumstances. Thus, the uncertainty associated with the introduction of the new currency is an argument in favor of relying less, rather than more, on monetary aggregates.

\subsection{An instrument rule instead of inflation targeting?}

Could the Eurosystem apply a simple instrument rule, where the instrument is specified as a simple function of a few observed macrovariables? Frequently discussed instrument rules include those of Taylor [75] and Henderson and McKibbin [43]. Could the Eurosystem simply implement those? If it did, it would seem to be the first time in monetary history. In practice, no central bank follows an explicit instrument rule, in the sense of being committed ex ante to a particular instrument rule.

Such behavior would correspond to "interest-rate targeting," in the following sense. Let the variable $\rho_{t} \equiv \sum_{\tau=0}^{\infty}\left(i_{t+\tau \mid t}-\pi_{t+\tau \mid t}-\bar{r}\right)$ which is approximately proportional to a long real interest rate, $r_{t}^{T}$, according to $\rho_{t} \approx T\left(r_{t}^{T}-\bar{r}\right)$, where $T$ is the maturity of the real interest rate. With high credibility, inflation expectations $\pi_{t+\tau \mid t}$ are approximately equal to the inflation target, so $\rho_{t} \approx \sum_{\tau=0}^{\infty}\left(i_{t+\tau \mid t}-\pi^{*}-\bar{r}\right)$ and potentially more strongly affected by expected future short nominal rates than when expectations are more variable. 
period-loss function be

$$
L_{t}=\frac{1}{2}\left(i_{t}-i_{t}^{*}\right)^{2}
$$

where $i_{t}^{*}$ is a time-varying interest-rate target, a time-varying target-level for the central bank's instrument, a short interest rate. For instance, let the interest rate be given by a Taylor rule with interest smoothing,

$$
i_{t}^{*} \equiv \rho i_{t-1}+(1-\rho)\left[\bar{r}+\pi^{*}+1.5\left(\pi_{t}-\pi^{*}\right)+0.5 x_{t}\right]
$$

where $0<\rho<1$.

Clearly, a first-order-condition for minimizing (1) with the period loss function (40) is simply

$$
i_{t}=i_{t}^{*}
$$

I believe it is obvious that no central bank is committed to a period loss function of this kind, with a corresponding interest rate target. Every central bank would be likely to resist any attempt to commit it to such behavior. No central bank reacts in a prescribed mechanical way to a prescribed information set. Every central bank uses more information than what the frequently suggested simple rules rely on. As further discussed in Svensson [70] and [73], the role of simple or complex instrument rules, as opposed to "targeting rules", is, in practice, never to commit the banks to the rules. At most, they serve as base-lines, that is, as comparisons and frames of reference, for the actual policy and its evaluation. Thus, even under normal circumstances, they are not a substitute for a framework for policy decisions. Under the special circumstances at the onset of the EMU, it would obviously be a particularly formidable challenge to fix the parameters of a simple instrument rule, including the average real interest rate.

Even if central banks are not committed to follow a particular instrument rule, this does not exclude that central banks' behavior ex post may be similar to a simple instrument rule. If current inflation and the current output gap are approximate sufficient statistics for the state of the economy and together with the instrument constitute the major determinants of future inflation and the output gap, a central bank pursuing flexible inflation targeting will, in systematic way, react to current inflation and output ( for instance, as in (11) when $z_{t} \equiv 0$ ). But if additional variables are considered relevant determinants of future inflation and output gaps, such a central bank will also react to those determinants (as in (11) when $z_{t} \neq 0$ ).

Interestingly, Gerlach and Smets [40], Peersman and Smets [58] and Taylor [78] have already estimated and used variants of the simple Rudebusch and Svensson model [62] for the EMU 
area. Their results indicate that reaction functions similar to the Taylor rule are likely to perform reasonably well for the EMU. As for the United States, the reaction functions in Taylor [75] and Henderson and McKibbin [43], although not optimal, could thus perhaps serve as rough benchmarks, but not as rules, for the interest rates actually set by the Eurosystem.

\section{Exchange-rate management}

The EMU will be a more closed economy than the individual Member States of the EMU. What implications does this have for the exchange-rate management and the exchange-rate variability of the Euro relative to third-country currencies? This has been discussed at length in the literature, with regard to exchange-rate policy both relative to the currencies of the "outs," the countries in the European Union who are not members of the EMU (Greece, Sweden and the United Kingdom) and relative to the large currencies, the US dollar and the yen. ${ }^{45}$ Here, I will briefly discuss two issues, the institutional framework for exchange-rate policy in the EMU and the role of exchange rate policy under inflation targeting in a relatively closed economy.

\subsection{Exchange-rate policy in the EMU}

The institutional framework for exchange-rate policy in the EMU is specified in the Maastricht Treaty. As is widely known, this constitutes a major inconsistency in the Treaty. As almost every undergraduate economics student would know (but, it seems, not many legislators), monetary and exchange rate policy cannot be separated under free capital mobility. A particular monetary policy implies a particular exchange rate policy, and vice versa. ${ }^{46}$ Nevertheless, whereas the Maastricht Treaty has assigned monetary policy decisions to the Eurosystem, it has assigned decisions about exchange-rate policy for the Euro to the Council of the European Union, that is, in practice the Council of finance ministers of the EMU Member States.

More precisely, Article 109(1) in the Treaty specifies that the Council, "acting unanimously, may conclude formal agreements on an exchange rate system for the [Euro]." By a qualified majority, the Council may "adopt, adjust or abandon the central rates of the [Euro] within the exchange rate system." Furthermore, such decisions can only be taken after "consulting the ECB in an endeavour [emphasis added] to reach a consensus consistent with the objective of

\footnotetext{
${ }^{45}$ See, for instance, Persson and Tabellini [59] on the relation between ins and outs and Begg, Giavazzi and Wyplosz [5] on exchange rate policy relative to the rest of the world.

${ }^{46}$ This is most easily seen from uncovered interest parity, where expected depreciation is related to the interestrate differential between domestic and foreign interest rates. Thus, under free capital mobility, interest rates cannot be set independently of exchange rates, and vice versa.
} 
price stability." This seems to provide far from complete protection of the primary objective of price stability.

In addition, Article 109(2) specifies that, in the absence of an exchange rate system, the Council, acting by a qualified majority, "may formulate general orientations for exchange rate policy in relation to these [non-Community] currencies." Here, however, the primary objective seems better protected: "These general orientations shall be without prejudice to the primary objective of the Eurosystem to maintain price stability." Furthermore, in its meeting in Luxembourg, December 13, 1997, the European Council declared that such general orientations may be formulated "in exceptional circumstances, for example in the case of a clear misalignment...." and that these general orientations "should always respect the independence of the ESCB and be consistent with the primary objective of the ESCB to maintain price stability.." Still, it is not clear whether it is the council of finance ministers or the Eurosystem that decides whether a particular general orientation is without prejudice to the primary objective or not. ${ }^{47}$

Thus, the Maastricht Treaty contains a conspicuous inconsistency and a potential threat to the independence of the Eurosystem, by giving governments a potential direct influence over monetary policy. This need not be an innocuous inconsistency, with the rise of new socialdemocrat and/or leftist governments in the European Union (currently only Spain and Ireland have non-socialist or non-social-democrat governments), several of which have challenged the Eurosystem and called for lower interest rates and monetary policy aiming at increasing growth and employment. In particular, the new German chancellor and the finance ministers of Germany and France have been very vocal, the finance ministers also asking for exchange-rate target zones. This is certainly of some significance, given that the Maastricht Treaty gives the governments of the EMU the right to introduce such target zones. To quote the French finance minister, Strauss-Kahn [66],

“... we should also monitor developments in exchange markets, and stand ready to express views on these developments, as well as make use if necessary of the provisions of art. 109 of the Maastricht treaty. There is in my view no contradiction between price stability and the reasonable degree of exchange rate stability we should be aiming at, but this will obviously require close co-operation between the ministers of the Euro-11, whose responsibility for exchange rate policy is clearly stated in the

\footnotetext{
${ }^{47}$ The new Riksbank Law in Sweden provides a clever solution to this dilemma. Although the government gets to decide on the exchange rate system, the Riksbank gets to decide on the implementation of the exchange rate system, including central parities if there is a fixed exchange rate system. Thus, if the government tried to circumvent the objective of price stability written into the law by deciding on a fixed exchange rate system against a weak currency (or a basket of weak currencies), the Riksbank could still fulfill the price-stability objective by regularly revaluing the krona. Still, with regard to the exchange-rate policy (but not with regard to the primary objective and the independence of the Riksbank) the new law is a deterioration, in that the previous law allowed the Riksbank, as one of the few central banks in the world, to decide on the exchange-rate system itself.
} 
treaty, and the ECB, which has the duty of maintaining price stability. Or aim should be to make clear to our partners, and to the markets, that speculations about a 'European benign neglect' are entirely misplaced." [Emphasis added.]

"A reasonable degree of exchange rate stability between the dollar and the euro will not only be required on bilateral grounds. It will also be a public good for the world economy, that will benefit to [sic] a large number of countries with diversified trade and financial relations. Europe and the US will have a joint responsibility in delivering this public good, and... we should discuss with our American friends how best to avoid the coexistence of two large currency zones, whose degree of openness is limited, giving rise to a kind of 'reciprocal benign neglect'." 48

Thus, the classic time-consistency problem may not be dead in Europe. Short-run political manipulation of monetary policy cannot be excluded, either via political pressure on the Governing Council, or via decisions on exchange-rate management. The latter can appear either in the form of formal agreements with non-Community countries (although they do not seem very likely and require unanimity by the governments) or in the form of general orientations (which may be more likely and only requires qualified majority).

What is the best defence of the Eurosystem in the face of such an onslaught? I am afraid that the traditional instinctive reaction of many central bankers when attacked is to hide behind less transparency and more ambiguity. I believe this is an increasingly inappropriate and ineffective method of defense. Instead, I believe more transparency is a more appropriate defense and probably also more effective. As further discussed in section 6 , with clear targets, transparent explanations and, in particular, published inflation forecasts, the Eurosystem can explain its case more convincingly, and the critics are forced to be more specific. Do they want to change the targets; if so, do they understand the consequences? Do they believe that their own analyses and forecasts are better? Do they realize that exchange rate management could jeopardize the inflation target? Do they realize that flexible inflation targeting, to some extent, takes the stability of the output gap into account? More transparency would seem to help the Eurosystem win the debate and maintain its professional reputation and political legitimacy. ${ }^{49}$

Criticism of the Eurosystem and demands for a more expansionary policy can cause two unfortunate deviations from the appropriate policy. The Eurosystem may pursue a more restrictive policy to demonstrate its independence and attempt to gain or not to lose credibility. Or the Eurosystem may pursue a more expansionary policy than appropriate, in order to deflect criticism

\footnotetext{
${ }^{48}$ Strauss-Kahn gave his remarks at a CEPR meeting in London. In a previous CEPR Occasional Paper, Begg, Giavazzi and Wyplosz [5] had stated that "most of the time the European and the US authorities will treat the dollar-euro rate with benign neglect."

${ }^{49}$ I interpret the Swedish experience of the last few years as an example of how an open and transparent central bank essentially has won a similar debate with its critics.
} 
and avoid more substantial consequences. In both cases, it seems that high transparency would make it easier for the Eurosystem to stay the course and defend the appropriateness of its policy. Furthermore, high transparency would increase the incentive to stay the course, since deviations from the appropriate policy would be more easily discovered and the costs of associated losses of credibility would be higher.

\subsection{Exchange-rate management under inflation targeting}

Leaving the possibility of government interference in exchange-rate policy aside, what is the role of exchange-rate management under inflation targeting in a relatively closed economy like the EMU? In an open economy, the exchange rate channel is an essential part of the transmission mechanism for monetary policy. The exchange rate affects the target variables of monetary policy, inflation and the output gap, in different subchannels. There is a direct exchange rate channel via import prices to CPI inflation, with, normally, a relatively short lag. There are also indirect exchange rate channels. The real exchange rate affects aggregate demand, with a lag, which affects the output gap and, with another lag, inflation. The exchange rate also affects aggregate supply with a lag, since costs of production are affected by the costs of imported intermediate inputs, and wage compensation is affected by CPI changes caused by exchange rate changes.

The exchange rate is, in turn, affected by interest-rate differentials, foreign-exchange risk premia, various foreign disturbances, including the credibility of the inflation target and related expectations of future exchange rates. Therefore, the exchange rate is important under inflation targeting in an open economy, both in transmitting the effects of interest rate setting and in transmitting various disturbances. Since some foreign disturbances are transmitted through the exchange rate, and the exchange rate affects CPI inflation, there is some element of stabilizing exchange rates under CPI-inflation targeting. ${ }^{50} 51$

In a more closed economy, the importance of the exchange rate and the exchange rate channel

\footnotetext{
${ }^{50}$ More specifically, from results in Svensson [71], there seems to be a considerable amount of inherent exchangerate stabilization under flexible CPI-inflation targeting. In contrast, under strict CPI-inflation targeting, when CPI inflation is the only target variable in the central bank's loss function, the loss function is minimized if CPI inflation is stabilized at the shortest possible horizon. Since the direct exchange rate channel seems to be the channel with the shortest transmission lag, this implies considerable reliance on exchange rate movements to stabilize CPI-inflation via compensating movements of import prices. This seems to result in high variability not only of nominal and real exchange rates but also the output gap and other variables than CPI inflation. Thus, with some weight on the stability of other variables than CPI inflation, strict inflation targeting appears to be an unsuitable policy. Flexible CPI-inflation targeting, with some weight on output-gap stability, implies targeting inflation at a longer horizon and seems to achieve a good compromise between stabilizing CPI inflation, the output gap and the real exchange rate.

51 Brash [10] provides an illuminating discussion of exchange-rate problems under inflation targeting in New Zealand.
} 
is obviously smaller. Intuition suggests that exchange-rate variability is likely to be larger under inflation targeting in a relatively closed economy compared to a relatively open one, since the impact on the CPI will be less and the need to stabilize the exchange rate to stabilize CPI inflation will be less. ${ }^{52}$

Variable real exchange rates can, of course, also cause problems in a relatively closed economy, for instance, by causing variability in the relative size of the tradable and nontradable sectors. In principle, flexible inflation targeting need not be inconsistent with some weight on real exchange rate stability. In the same way as we can consider an output gap in (5), we can consider a real exchange-rate gap, $q_{t}-q_{t}^{n}$, where $q_{t}$ is the log real exchange rate in period $t$ and $q_{t}^{n}$ is a log "natural" real exchange rate, although estimating a natural real exchange rate may be more difficult than estimating a potential output level, for instance because it may be more variable. Given an appropriately estimated real exchange rate, flexible inflation targeting can be consistent with a period loss function of the form

$$
L_{t}=\frac{1}{2}\left[\left(\pi_{t}-\pi^{*}\right)^{2}+\lambda\left(y_{t}-y_{t}^{n}\right)^{2}+\lambda_{q}\left(q_{t}-q_{t}^{n}\right)^{2}\right]
$$

with some weight $\lambda_{q}$ on stabilizing the real exchange rate. Of course, any bias in estimates of the natural real exchange rate, as for estimates of the potential output level, would potentially result in a (positive or negative) inflation bias. A loss function like (43) might be equivalent to a loss function with some weight on stabilizing the output gaps in the tradable and nontradable sectors separately. The result of (43) would generally be some stabilization of the real exchange rate at the cost of some increased variability of inflation, that is, the output gap, or both.

Although such inclusion of real exchange rate stability is not inconsistent with flexible inflation targeting, it is associated with several difficulties. The problem of estimating the natural real exchange rate and corresponding risks for the average inflation bias has already been mentioned. Another is the transparency of the regime. Generally, transparency would tend to be smaller, and the amount of discretion larger, the more target variables there are in the loss function. It seems that the Eurosystem would probably be wise to avoid considering the real exchange rate too much (beyond its effect on EMU-wide inflation and the output gap), except perhaps if serious misalignments seem to result (to the extent that these can be identified and verified). (This would mean that the real exchange rate still enters the loss function, although in some more complicated, nonlinear way, that need not affect monetary policy in normal times.)

\footnotetext{
${ }^{52}$ Still, as examined in Martin [53] and discussed in Begg, Giavazzi and Wyplosz [5] and Begg [3], the relation need not necessarily be monotionic.
} 
That flexible inflation targeting can, to some extent, incorporate some weight on real exchange rate stabilization does, of course, not make the problem with the control of exchange rate policy in the EMU less serious. For one thing, "stabilizing the exchange rate" is, in practice, likely to mean either "preventing a real appreciation" or "achieving a real depreciation" for the finance ministers concerned in EMU, with all the accompanying inflation-bias consequences.

\section{Transparency}

\subsection{The general role of transparency in monetary policy}

What is the role of transparency in monetary policy? Consider the following three-part scheme for efficient delegation of monetary policy in a democratic society: (1) society (the collective of the citizens) announces goals for monetary policy, (2) the central bank receives instrument independence to pursue the goals without short-term political inference, and (3) the central bank is accountable to society for fulfilling the goals. Transparency of the goals and the policy is then crucial for the accountability of the central bank, that is, for society's monitoring and evaluation of monetary policy. Transparency thus improves the central bank's incentives to pursue the announced goals. Transparency may also facilitate public understanding of monetary policy and make monetary policy more predictive, which may stabilize inflation expectations and increase the credibility of monetary policy. Improved public understanding and increased credibility is likely to facilitate the implementation of monetary policy and thereby contribute to the achievement of the goals. ${ }^{53}$

This view of the role of transparency is supported in recent work by Faust and Svensson [34]. Building on a previous work by Cukierman and Meltzer [22], Faust and Svensson examine the role of transparency in a model with a central bank that is tempted to deviate from an announced inflation target due to fluctuations in an idiosyncratic component of the bank's goals, exemplified by an employment target. The employment target is private information to the central bank and unobservable to the private sector. For instance, it represents changes in the composition of the Board, or the response of the bank to external pressure from various special interests. The private sector observes the macroeconomic outcome and imperfectly infers the central bank's employment target, which inference affects the bank's reputation in the private sector and the corresponding private-sector inflation expectations.

\footnotetext{
${ }^{53}$ See section 4 on the benefits of increased credibility.
} 
Increased transparency allows the private sector to infer the bank's employment target with greater precision, which makes the bank's reputation and the corresponding private-sector inflation expectations more sensitive to the bank's actions. This, in turn, increases the cost for the bank of deviating from the announced inflation target and pursuing its idiosyncratic employment target. Consequently, increased transparency induces the bank to follow the announced policy more closely. It simply provides an implicit commitment mechanism that reduces the bank's discretion to deviate from the announced policy. ${ }^{54}$

Faust and Svensson show that society almost always prefers more transparency to less, whereas the central bank often prefers less transparency to more, since this gives the bank more discretion to pursue its idiosyncratic goals with less cost to its reputation. An obvious conclusion from this finding is that society, rather than the central bank, should decide on the degree of transparency.

\subsection{Transparency of Eurosystem monetary policy}

To what extent is the Eurosystem accountable, and how transparent should it be? ${ }^{55}$ Article 105(1) in the Maastricht Treaty announces the goal for monetary policy. This corresponds to part (1) of the three-part delegation of monetary policy referred to above, if the Maastricht Treaty is interpreted as reflecting the European society. The Maastricht Treaty also specifies the independence of the Eurosystem, corresponding to part (2) of the delegation. Since the announcement of the goal in article 105(1) is not sufficiently specific to be operational, the independence of the Eurosystem also includes its formulating operational goals consistent with the general goal. Whereas the Maastricht Treaty hence takes care of part (1) and part (2), it is unfortunately rather weak on part (3), the accountability of the Eurosystem. Article 109b(3) only specifies that the ECB shall present an annual report of the activities of the Eurosystem to the European Parliament (EP), the Council of the European Union and the European Commission, and that the members of the Executive Board may be heard by committees of the European Parliament, at the EP's or at their own initiative. Article 15 of the Protocol (No 3)

\footnotetext{
${ }^{54}$ McCallum [54] has expressed doubts about the relevance of discretion equilibria and argued that central banks can achieve the commitment equilibrium and "just do it," although without specifying a mechanism which would make such behavior consistent with an equilibrium. The results of Faust and Svensson [34] can be interpreted as suggesting such a mechanism.

${ }_{55}^{5}$ For more discussion of the accountability and transparency of the Eurosystem, see Begg [3], Begg, De Grauwe, Giavazzi, Uhlig and Wyplosz [4], Bini Smaghi [8] and Blanchard, Gros, Emerson, Mayer, Saint-Paul, Sinn and Tabellini [42]. Buiter [15] and [16] has critized the Eurosystem with regard to its accountability and transparency and compared it unfavorably with Bank of England; Issing [45] and Duisenberg [26] have defended the Eurosystem. For general discussions of central-bank accountability and transparency, see Briault, Haldane and King [11] and de Haan, Amtenbrink and Eijffinger [24].
} 
on the Statute of the European System of Central Banks and of the European Central Bank also mandates an, at least quarterly, report on the activities of the Eurosystem (the Eurosystem has, in effect, announced the publication of a monthly bulletin). The Treaty imposes no specific transparency requirement on the Eurosystem with regard to the contents of the reports, and even includes a clause that can be used in order to reduce the transparency and accountability of the Eurosystem. ${ }^{56}$ Thus, nothing prevents the Eurosystem from publishing voluminous reports with little actual content, a practice which is not unheard of among central banks. The Treaty leaves the impression that its drafters and signers have not understood, or not accepted, the role of transparency and accountability for creating the best incentives towards fulfilling the goals of society. In contrast, New Zealand's Reserve Bank Act of 1989 contains detailed instructions for the mandatory 6-monthly Monetary Policy Statements by the Reserve Bank (section 15), and the new Bank of England Bill mandates publication of minutes and voting records of the Monetary Policy Committee and a quarterly report, the Inflation Report. The Act and the Bill are, of course, very explicit on the accountability of the banks.

The EP may be the natural institution to which the Eurosystem should be accountable. The Maastricht Treaty already gives the EP the right to arrange hearings with the president and the other members of the Eurosystem's Executive Board. Tabellini [74] has provided a complete scheme according to which the EP could take the initiative and hold the Eurosystem accountable in an effective way, and in this way, organize the third part of the three-part delegation scheme more satisfactorily. Tabellini suggests that the EP should insist on the Eurosystem publicly announcing an inflation target and then hold the Eurosystem accountable for achieving that inflation target. After the Eurosystem's recent announcement of its definition of price stability, the 1-2 percent range and the 1.5 percent point inflation target (or the $0-2$ percent range and the 1 percent point target) can serve as this inflation target. Tabellini also suggests that the EP should discard any announcement of any intermediate monetary targets, which is obviously supported by the above criticism of the Eurosystem's proposed reference value. The EP could insist on receiving a periodic Inflation Report, similar to those produced by the inflation-targeting central banks. This report would then explain and motivate policy decisions, describe current inflation trends, and include quantitative inflation forecasts. The EP would then evaluate monetary policy decisions by comparing the inflation forecasts with the inflation target. If current

\footnotetext{
${ }^{56}$ Article 10.4 in the Protocol No. 3 annexed to the Mastricht Treaty states: "The proceedings of the meetings [of the Governing Council] shall be confidential. The Governing Council may decide to make the outcome of its deliberations public."
} 
inflation deviates sufficiently from the inflation target in either direction, the EP could request a specific explanation from the Eurosystem and obtain assurances about the appropriate action. The reporting procedure could fruitfully be institutionalized through an agreement between the Eurosystem and the EP.

Tabellini's suggestion seems to be a very effective way of improving the accountability of the Eurosystem. The EP could thus establish a practice of close scrutiny of the Eurosystem, for instance with a committee of appointed experts that holds hearings with members of the Executive Board and the Governing Council, demands access to all information, and writes thorough regular reports evaluating the performance of the Eurosystem, including the appropriateness of its targets, the framework for policy decisions and communication with outsiders and the general public. This could establish the accountability part of the three-part delegation in a satisfactory way. A great advantage with Tabellini's suggestion is that it could be done at the initiative and the insistence of the EP, which should have an incentive in raising its profile and establishing itself as an effective surveillor of the Eurosystem.

What degree of transparency would be required for efficient external monitoring and evaluations of the Eurosystem policy? Minimum requirements would seem to include (i) transparent targets and framework for policy decisions, (ii) transparent motivations of policy decisions, and (iii) transparent explanations and discussion by the Eurosystem of outcomes relative to targets. With regard to (i), the Eurosystem would need to clarify the lower bound and the midpoint in the definition of price stability. It could also be more transparent about the role of the output gap. With regard to the framework for policy decisions, the emphasis on the reference value for monetary growth is misleading and designed to reduce transparency. Instead, the Eurosystem would have to be explicit about the crucial role of conditional forecasts of inflation and the output gap. With regard to (ii), given the crucial role of conditional forecasts in forward-looking medium-term monetary policy, the best motivation of interest changes or the absence thereof is with reference to conditional forecasts, especially an unchanged-interest-rate inflation forecast. Thus, the Eurosystem would have to publish its forecasts, and use them to motivate its policy. Motivations with reference to deviations between monetary growth and the reference value are likely to be misleading and reduce transparency. With regard to (iii), the most relevant deviation is the one between actual inflation and previous forecasts and the reasons for such deviations, whether they are due to unanticipated shocks or errors in data, models or judgement. Again, such deviations cannot be discussed without published forecasts. The transparency of Eurosys- 
tem monetary policy would seem to be well served by a regular publication, a Price Stability Report, modeled on the high-quality Monetary Policy Statements and Inflation Reports issued by the Reserve Bank of New Zealand, Bank of England and Sveriges Riksbank.

Increased transparency and published forecasts will reduce the discretion of the Eurosystem, more clearly reveal any errors and mistakes, and prompt its staff, Executive Board and Governing Council to work harder and better. This may be perceived as demanding and disadvantageous by the Eurosystem (but, of course, not by society). Still, there are some direct benefits from transparency for the Eurosystem. For instance, the debate on monetary policy may improve. Criticism of monetary policy may have to specify whether it refers to the numerical inflation target, the quality and the potential bias of Eurosystem forecasts, or something else. Respectable requests for lower interest rates must be accompanied by an argument why Eurosystem forecasts are biased, or why targets should be changed. The Eurosystem's target becoming widely accepted and its analysis becoming widely respected, should provide the best protection from short-run political pressure. In particular, the Eurosystem may more easily defend itself against the current onslaught of political interference on interest-rate setting and exchange-rate policy, see the discussion in section 5.1.

The publication of minutes has been intensively discussed. Effective monitoring and evaluation of monetary policy decisions would seem to require knowledge about the amount and quality of information available for those decisions and the quality of the analysis and discussion preceding the decisions. This is a strong argument for the publication of the material available to the Governing Council and the minutes from its discussions. Only then can outsiders make sure that the analysis, discussion and decisions are of appropriate quality. Published minutes would also provide the best information about the decision procedure and the information taken into account, and this way make monetary policy more predictable.

An argument used against publishing minutes is that it might deter honest and frank discussion and possibly move such discussion outside the meetings. Non-attributed minutes, however, would reduce or remove such deterrence. Sufficient personal integrity of and peer pressure among Governing Council members may also prevent discussions from moving elsewhere.

Another contentious issue is the publication of voting records. Without voting records, it will be impossible for less informed outsiders to evaluate the quality of decisions by individual Governing Council members. Published voting records would then improve incentives for good decisions. Conspicuous deviations from the analyses and inflation forecasts will then not go 
unnoticed.

An argument used against publishing voting records is that they might increase national political pressure on national governors to adopt a national rather than an EMU-wide perspective. As noted by Buiter [15] and [16], however, national governments are likely to know the voting record in any case, so not publishing voting records would not protect national governors from secret pressure from national governments. Published voting records would then make it more difficult for such pressure to go unnoticed, in that conspicuous deviations from the message of received analyses and forecasts would be more easily spotted. Furthermore, transparent targets, analyses and forecasts together with published voting records may actually make it easier for national governors to defend their votes and resist pressure and therefore provide the best protection against national pressure.

Could there be too much transparency? From the point of view of the Eurosystem, transparency would more easily reveal mistakes in data, models or judgements, including imperfections in the Eurosystem understanding of the transmission mechanism. Although this may cause the Eurosystem some embarrassment at times, at the same time, it provides strong incentives for the Eurosystem to improve the quality of its analysis and its understanding. This is likely to be beneficial to society. Could too much transparency give an exaggerated impression of the precision of the forecasts of the Eurosystem and its degree of control of inflation? Hardly, since the Eurosystem has very strong incentives to always emphasize the size of potential forecast errors and the limited degree of control, in order to avoid future embarrassment. It seems that too much transparency could only be counterproductive if it inhibits honest and frank discussions. Still, nonattributed minutes and honest reports of uncertainty and likely forecast errors need not inhibit such discussion. ${ }^{57}$

One might wish that central banks in general, and the Eurosystem in particular, would choose openness and transparency as the default case, and only resort to secrecy and obfuscation when the arguments for this are strong. Unfortunately, central-bank tradition is usually the other way around, with the few inflation-targeting central banks being very recent exceptions. In case the Eurosystem should choose secrecy and obfuscation rather than transparency and accountability, which, given the prominent role for the reference value and the insistence on secret

\footnotetext{
${ }^{57}$ It has been suggested that the time input required by a central bank's most qualified officials would be a significant cost of transparency. Still, the cost of hiring additional information officials for the necessary external contacts would be neglible compared to the tens of thousands of people already employed by the Eurosystem. Besides, the top officials give many speeches and interviews already; the difference may be more in the substance than in the number of engagements.
} 
inflation forecasts cannot be excluded, the best solution for outside monitoring, as suggested by Tabellini [74], may be that the European Parliament, the general public and other outsiders evaluate monetary policy performance as if the ECB had an explicit inflation target. With unpublished conditional inflation forecasts, monetary policy can still be monitored by comparing reputable outside forecasts with the inflation target. For instance, if the Eurosystem refuses to cooperate, the European Parliament can organize their own committee of forecasters as part of the evaluation of the Eurosystem. In any case, independent bodies of experts will play a crucial part in scrutinizing and evaluating ECB monetary policy and, fortunately, several such bodies have already been formed. ${ }^{58}$

\section{Conclusions}

As noted above, there are many sensible aspects of the Eurosystem's monetary strategy, for instance, the choice of the MUICP (which does not include interest-rate costs) as the main index, the focus on the Euroarea as a whole, the warning about unavoidable and uncontrollable short-term volatility of prices, the emphasis on the medium term, and the rejection of moneygrowth targeting. Still, the strategy proposed has a number of conspicuous deficiencies.

After clarifications by the Eurosystem and the announcement of the reference value, there is still some ambiguity with regard to the definition of price stability. It is strange that observers should have to piece together the definition from different statements, including the announcement of the reference value. It seems that any remaining ambiguity with regard to the definition serves no purpose. Public understanding of ECB policy would seem to be facilitated by replacing the ambiguous and asymmetric statement "below 2 percent" by an unambiguous and symmetric inflation target, by clarifying the lower bound and the midpoint, possibly with the addendum that this definition may be slightly modified, when more evidence about the quality of the MUICP becomes available. In the absence of such a clarification, observers should probably, for the time being, interpret and evaluate the Eurosystem as having an inflation target of $1-1.5$ percent.

If monetary policy is to be effective, the Eurosystem needs to develop its capacity to make the "broadly based assessments of the outlook for future price developments," that is, to construct conditional inflation forecasts. It also needs to be able to construct output-gap forecasts,

\footnotetext{
${ }^{58}$ Three such independent bodies have been announced to date, organizied by CEPR [4] in London, CEPS [42] in Brussells, and ZEI [82] in Bonn.
} 
in order to evaluate consequences of its policy for output-gap stability and to find the appropriate gradualist and measured response to disturbances. If its conditional inflation forecast for unchanged interest rates overshoots or undershoots the inflation target at the relevant horizon, probably 1.5-2.5 years, the Eurosystem would normally need to adjust its repo rate.

For policy to be effective, the weights given to different indicators should be derived from their predictive power in the broadly based assessment of the outlook for future price development, that is, the conditional inflation forecast, as well as in the conditional output-gap forecast. There is no convincing case for giving money a primary role beyond that motivated by its weight in the broadly based assessment. Indeed, the deviation of money growth from the reference value is likely to be a redundant, or even misleading, indicator. Clarity and transparency of the Eurosystem monetary policy may be best served by letting the reference value fade into oblivion, unless new surprising evidence to the contrary is found. For the time being, observers should probably just disregard statements about the reference value.

Whether new information warrants an adjustment of the repo rate depends on whether the new information affects the conditional inflation and output-gap forecasts. In this way, new information is "filtered through the forecasts."

Thus, the conditional inflation and output-gap forecasts, including how they are affected by new information and disturbances, will in practice be the decisive input in Eurosystem decisions about the repo rate. Therefore, clarity and transparency would seem to be best served if the Eurosystem were also to use the conditional forecasts in its announcements to motivate its policy. This, in turn, requires published forecasts, with the corresponding assumptions and analyses. Otherwise, outside observers' evaluation of Eurosystem policy is made unnecessarily difficult. Without such a publication, the information made available by the Eurosystem, in spite of its volume and frequency, will in effect have much less content. Observers will then, to a large extent, have to rely on outside forecasts to evaluate policy. Publishing the forecasts is also likely to provide the best incentive for the Eurosystem to improve its understanding of the transmission mechanism and the quality of the forecasts, and, in this way, improve the quality of its policy.

Transparency and accountability is thus likely to be best served by publishing non-attributed minutes of the General Council, including voting records, as is currently done by Bank of England, the Federal Reserve System, Sveriges Riksbank and several other central banks.

Generally, it is difficult to find any good reason why the Eurosystem should set lower stan- 
dards with regard to intellectual coherence, analysis and transparence than the best practice of current inflation-targeting central banks. It also seems that the European Parliament would gain a great deal from making its monitoring and evaluation of the Eurosystem in line with the best current practice. 


\section{References}

[1] Akerlof, George A., William T. Dickens and George L. Perry (1996), "The Macroeconomics of Low Inflation," Brookings Papers on Economic Activity 1:1996, 1-76.

[2] Ball, Laurence (1997), "Efficient Rules for Monetary Policy," NBER Working Paper No. 5952.

[3] Begg, David (1997), “The Design of EMU," IMF Working Paper WP/97/99.

[4] Begg, David, Paul De Grauwe, Francesco Giavazzi, Harald Uhlig, and Charles Wyplosz (1998), The ECB: Safe at any Speed?, Monitoring the European Central Bank 1, CEPR, London.

[5] Begg, David, Francesco Giavazzi and Charles Wyplosz (1997), "Options for the Future Exchange Rate Policy of the EMU," CEPR Occasional Paper No. 17, CEPR, London.

[6] Bernanke, Ben S., Thomas Laubach, Frederic S. Mishkin, and Adam S. Posen (1998), Inflation Targeting: Lessons from the International Experience, manuscript.

[7] Bernanke, Ben S., and Ilian Mihov (1997), "What Does the Bundesbank Target?" European Economic Review 41, 1025-1054.

[8] Bini Smaghi, Lorenzo (1998), "The Democratic Accountability of the European Central Bank," Banca Nazionale de Lavoro Quarterly Review 51, 119-143.

[9] Brainard, William (1967), "Uncertainty and the Effectiveness of Policy," American Economic Review 57, Papers and Proceeding, 411-425.

[10] Brash, Donald T. (1999), "The New Zealand Dollar and the Business Cycle," speech, January 29, 1999.

[11] Briault, Clive, Andrew Haldane, and Mervyn King (1997), "Independence and Accountability," in Iwao Kuroda, ed, Towards More Effective Monetary Policy, St. Martin's Press, New York.

[12] Brunner, Karl, and Allan H. Meltzer (1967), "The Meaning of Monetary Indicators," in G. Horwich, ed., Monetary Process and Policy, Irwin, Homewood, Ill., 187-217.

[13] Brunner, Karl, and Allan H. Meltzer (1969), "The Nature of the Policy Problem," in Karl Brunner, ed., Targets and Indicators of Monetary Policy, Chandler, San Francisco, 1-26.

[14] Bryant, Ralph C. (1980), Money and Monetary Policy in Interdependent Nations, Brookings, Washington, DC.

[15] Buiter, Willem H. (1998), Letter to the Editor, Financial Times, September 24, 1998.

[16] Buiter, Willem H. (1999), "Alice in Euroland," CEPR Policy Paper No. 1.

[17] Bundesbank (1996), Annual Report 1995, Deutsche Bundesbank.

[18] Bundesbank (1998), Monthly Report January 1998, Deutsche Bundesbank.

[19] Cabrero, Alberto, José Luis Escrivá, Emilio Muños, and Juan Peñalosa (1998), "The Controllability of a Monetary Aggregate in EMU", Working Paper No. 9817, Banco de Espana. 
[20] Clarida, Richard, Jordi Gali, and Mark Gertler (1998), "Monetary Policy Rules in Practice: Some International Evidence," European Economic Review 42, 1033-1067.

[21] Clarida, Richard, and Mark Gertler (1997), "How the Bundesbank Conducts Monetary Policy," in Romer, Christina, and David Romer, eds., Reducing Inflation: Motivation and Strategy, Chicago University Press.

[22] Cukierman, Alex, and Allan H. Meltzer (1986), "A Theory of Ambiguity, Credibility, and Inflation under Discretion and Asymmetric Information," Econometrica 54, 1099-1128.

[23] De Grauwe, Paul (1998), "ECB is Law unto Itself," Financial Times, November 12, 1998.

[24] de Haan, Jakob, Fabian Amtenbrink, and Sylvester C.W. Eijffinger (1998), "Accountability.of Central Banks: Aspects and Quantification," CentER Discussion Paper No. 9854.

[25] Dornbusch, Rudi, Carlo Favero, and Francesco Giavazzi (1998), "Immediate Challenges for the European Central Bank," Economic Policy 26, 15-64.

[26] Duisenberg, Willem F. (1998a), "The ESCB's Stability-Oriented Monetary Policy Strategy," speech in Dublin, November 10, 1998.

[27] Duisenberg, Willem F. (1998b), "The Stability-Oriented Monetary Policy Strategy of the European System of Central Banks and the International Role of the Euro," speech in New York, November 12, 1998.

[28] Estrella, Arturo, and Frederic S. Mishkin (1997), "Is there a Role for Monetary Aggregates in the Conduct of Monetary Policy?" Journal of Monetary Economics 40, 279-304.

[29] European Central Bank (1998), "The Quantitative Reference Value for Monetary Growth," Press Release, December 1, 1998, http://www.ecb.int.

[30] European Central Bank (1998), "A Stability-Oriented Monetary Policy Strategy for the ESCB," Press Release, October 13, 1998, http://www.ecb.int.

[31] European Central Bank (1999), "The Stability-Oriented Monetary Policy Strategy of the Eurosystem," ECB Monthly Bulletin, January 1999, http://www.ecb.int, 39-50.

[32] European Monetary Institute (1997), The Single Monetary Policy in Stage Three: Elements of the Monetary Policy Strategy in the ESCB, European Monetary Institute.

[33] European Parliament (1998), Hearing of candidates to the Board of the ECB, 7 and 8 May 1988, Committee on Economic and Monetary Affairs and Industrial Policy, European Parliament.

[34] Faust, Jon W., and Lars E.O. Svensson (1999), "Credibility and Transparency: Monetary Policy with Unobservable Goals," Working Paper.

[35] Federal Reserve Bank of Kansas City (1996), Achieving Price Stability, Federal Reserve Bank of Kansas City.

[36] Financial Times (1998), "ECB: Flexible Strategy Set for EMU,” October 14, 1998.

[37] Freedman, Charles (1996), "What Operating Procedures Should Be Adopted to Maintain Price Stability?" in Federal Reserve Bank of Kansas City [35]. 
[38] Friedman, Benjamin M. (1975), "Targets, Instruments, and Indicators of Monetary Policy," Journal of Monetary Economics 1, 443-473.

[39] Gerlach, Stefan (1994), "German Unification and the Demand for German $\mathrm{M}_{3}$," BIS Working Paper No. 21.

[40] Gerlach, Stefan, and Frank Smets (1998), "Output Gaps and Monetary Policy in the EMU Area," European Economic Review, forthcoming.

[41] Gordon, Robert J. (1996), "Comments and Discussion," Brookings Papers on Economic Activity 1:1996, 60-66.

[42] Gros, Daniel, Oliver Blanchard, Michael Emerson, Thomas Mayer, Hans Werner Sinn, Gilles St. Paul and Guido Tabellini (1998), "Macroeconomic Policy in the First Year of Euroland," First Annual Report on the European Economy of the CEPS Macroeconomic Policy Group, Centre for European Poicy Studies, Brussells.

[43] Henderson, Dale W., and Warwick J. McKibbin (1993), "A Comparison of Some Basic Monetary Policy Regimes for Open Economies: Implications of Different Degrees of Instrument Adjustment and Wage Persistence," Carnegie-Rochester Conference Series on Public Policy 39, 221-317.

[44] Issing, Otmar (1997), "Monetary Targeting in Germany: The Stability of Monetary Policy and of the Monetary System," Journal of Monetary Economics 39, 67-79.

[45] Issing, Otmar (1998a), "Open for Business," Financial Times, September 22, 1998.

[46] Issing, Otmar (1998b), "Monetary Policy in EMU," speech, October 13, 1998.

[47] Issing, Otmar (1998c), "The European Central Bank at the Eve of EMU," speech November $26,1998$.

[48] Issing, Otmar, and Karl-Heinz Tödter (1995), "Geldmenge und Preise im vereinten Deutschland," in D. Duwendag, ed., Neuere Entwicklungen in der Geldtheorie und Währungspolitik, Duncker and Humblot, Berlin.

[49] Kareken, John H., Thomas Muench and Neil Wallace (1973), "Optimal Open Market Strategy: The Use of Information Variables," American Economic Review 63 (1973), 156-172.

[50] Laubach, Thomas, and Adam S. Posen (1997), Disciplined Discretion: Monetary Targeting in Germany and Switzerland, Essays in International Finance, No. 206, Princeton University.

[51] Leiderman, Leonardo, and Lars E.O. Svensson, eds. (1995), Inflation Targets, Centre of Economic Policy Research, London.

[52] Lohmann, Susanne (1996), "Why Do Central Banking Institutions Matter?" Working Paper, University of California, Los Angeles.

[53] Martin, Phillippe (1997), "The Exchange Rate Poicy of the Euro: A Matter or Size?" CEPR Discussion Paper No. 1646.

[54] McCallum, Bennett T. (1997), "Crucial Issues Concerning Central Bank Independence," Journal of Monetary Economics 39, 99-112. 
[55] Neumann, Manfred (1997), "Monetary Targeting in Germany," in Kuroda, Iwao, ed., Towards More Effective Monetary Policy, St. Martin's Press, New York.

[56] Obstfeld, Maurice (1998), "EMU: Ready or Not?" Essays in International Finance No. 209, Princeton University.

[57] Orphanides, Athanasios, and Volker Wieland (1998), "Price Stability and MonetaryPolicy Effectiveness when Nominal Interest Rates Are Bounded at Zero," WorkingPaper, Federal Reserve Board.

[58] Peersman, Gert, and Frank Smets (1998), "The Taylor Rule: A Useful Monetary Policy Guide for the ECB?" paper presented at Banca d'Italia worskhop on "Monetary Policy of the ESCB: Strategic and Implementation Issues," 6-7 July 1998.

[59] Persson, Torsten, and Guido Tabellini (1996), "Monetary Cohabitation in Europe," NBER Working Paper No. 5532.

[60] Posen, Adam (1998), "No Monetary Masquerade for the ECB," in Ellen Meade, ed., The European Central Bank: How Accountable? How Decentralized?, American Institute for Contermporary German Studies, Washington, forthcoming.

[61] Ramaswamy, Ramana, and Torsten Sloek (1997), "The Real Effects of Monetary Policy in the European Union: What are the Differences?" IMF Working Paper WP/97/160.

[62] Rudebusch, Glenn, and Lars E.O. Svensson (1998), "Policy Rules for Inflation Targeting," in Taylor [77], forthcoming.

[63] Rudebusch, Glenn, and Lars E.O. Svensson (1999), "Empirical Evidence on Targeting Money: Data from the U.S. and Lessons for the Eurosystem," in preparation.

[64] Schmid, Peter (1998), "Monetary Targeting in Practice: The German Experience," Working Paper, Deutsche Bundesbank.

[65] Stock, James H., and Mark W. Watson (1998), "Forecasting Inflation," Working Paper.

[66] Strauss-Kahn, Dominique (1998), "Remarks," presented at CEPR, London, on November 9, 1998.

[67] Svensson, Lars E.O. (1996), "Commentary: How Should Monetary Policy Respond to Shocks while Maintaining Long-Run Price Stability?-Conceptual Issues," in Federal Reserve Bank of Kansas City [35].

[68] Svensson, Lars E.O. (1997a), "Inflation Forecast Targeting: Implementing and Monitoring Inflation Targets," European Economic Review 41, 1111-1146.

[69] Svensson, Lars E.O. (1997b), "Inflation Targeting: Some Extensions," NBER Working Paper No. 5962. Scandinavian Journal of Economics, forthcoming.

[70] Svensson, Lars E.O. (1999a), "Inflation Targeting as a Monetary Policy Rule," Journal of Monetary Economics, forthcoming.

[71] Svensson, Lars E.O. (1999b), "Open-Economy Inflation Targeting," Journal of International Economics, forthcoming. 
[72] Svensson, Lare E.O. (1999c), "Price Level Targeting vs. Inflation Targeting," Journal of Money, Credit and Banking, forthcoming.

[73] Svensson, Lars E.O. (1999d), "Price Stability as a Target for Monetary Policy: Defining and Maintaining Price Stability," Working Paper, http://www.iies.su.se/leosven.

[74] Tabellini, Guido (1998), "Inflation Targeting and the Accountability of the European Central Bank," statement prepared for a hearing organized by the Subcommitte on Monetary Affairs, European Parliament, January 6, 1998.

[75] Taylor, John B. (1993), "Discretion versus Policy Rules in Practice," Carnegie-Rochester Conference Series on Public Policy 39, 195-214.

[76] Taylor, John B. (1998a), "A Historical Analysis of Monetary Policy Rules," in Taylor [77], forthcoming.

[77] Taylor, John B., ed. (1998b), Monetary Policy Rules, Chicago University Press, forthcoming.

[78] Taylor, John B., (1998c), "The Robustness and Efficiency of Monetary Policy Rules as Guidelines for Interest Rate Setting by the European Central Bank," IIES Seminar Paper No. 649.

[79] von Hagen, Jürgen (1995), "Inflation and Monetary Targeting in Germany," in Leiderman and Svensson [51].

[80] von Hagen, Jürgen (1998), “Money Growth Targeting,” IIES Seminar Paper No. 643.

[81] Wolters, Jürgen, Timo Teräsvirta and Helmut Lütkepohl (1998), "Modeling the Demand for M3 in the Unified Germany," Review of Economics and Statistics 53, 399-409.

[82] ZEI (1998), "EMU Monitor: Press Statement," July 9, 1998, Zentrum für Europäische Integrationsforschung, University of Bonn. 
</ref_section> 